\title{
Multiple Channel Types Contribute to the Low-Voltage-Activated Calcium Current in Hippocampal CA3 Pyramidal Neurons
}

\author{
Robert B. Avery and Daniel Johnston \\ Division of Neuroscience, Baylor College of Medicine, Houston, Texas 77030
}

Hippocampal neurons exhibit low-voltage-activated (LVA) and high-voltage-activated (HVA) calcium currents. We characterized the LVA current by recording whole-cell $\mathrm{Ca}^{2+}$ currents from acutely isolated rat hippocampal CA3 pyramidal neurons in $2 \mathrm{~mm} \mathrm{Ca}^{2+}$.

Long depolarizing steps to $-50 \mathrm{mV}$ revealed two components to the LVA current: transient and sustained. The transient phase had a fast decay time constant of $59 \mathrm{msec}$. The sustained phase persisted throughout the depolarization, even for steps lasting several seconds. The transient current was inhibited by the classic T-type channel antagonists $\mathrm{Ni}^{2+}$ and amiloride. The anticonvulsant phenytoin preferentially blocked the sustained phase, but ethosuximide had no effect. Steady-state inactivation of the transient component was half-maximal at $-80 \mathrm{mV}$.

Nimodipine, an L-type channel antagonist, partly inhibited the sustained current. BayK-8644, an L-type channel agonist, potentiated the sustained current. Calciseptine, another L-type channel antagonist, inhibited the sustained component. $\omega$-Conotoxin-MVIIC, a nonselective toxin for HVA channels, had no effect on either of the LVA current components. $\omega$-Grammotoxin-SIA, another nonselective toxin, partially inhibited the sustained component. The voltage dependence of activation of the nimodipine-sensitive current could be fit with a single Boltzmann, consistent with a homogenous population of L-type channels in CA3 neurons. Half-maximal activation of the nimodipine-sensitive current occurred at $-30 \mathrm{mV}$, considerably more negative than the remaining HVA current.

These results suggest that in physiologic $\mathrm{Ca}^{2+}$ more than one type of $\mathrm{Ca}^{2+}$ channel contributes to the LVA current in CA3 neurons. The transient current is carried by T-type channels. The sustained current is carried, at least in part, by dihydropyridine-sensitive channels. Thus, the designation "low-voltage-activated" should not be limited to T-type channels. These findings challenge the traditional designation of L-type channels as exclusively HVA and reveal a possible role in subthreshold $\mathrm{Ca}^{2+}$ signaling.

Key words: calcium channels; hippocampus; CA3; whole-cell patch; low-voltage-activated; T-type; L-type; nimodipine; ethosuximide; phenytoin
Central neurons possess multiple types of voltage-gated calcium channels (Llinás and Yarom, 1981; Fisher et al., 1990). On the basis of the membrane potentials at which they become active, $\mathrm{Ca}^{2+}$ channels have been classified as either low-voltage-activated (LVA) or high-voltage-activated (HVA; Llinás and Yarom, 1981; Carbone and Lux, 1984). LVA channels can be opened by small depolarizations that may be subthreshold for action-potential generation. The only member of the LVA group has been the T-type $\mathrm{Ca}^{2+}$ channel. The specific cellular functions of different types of $\mathrm{Ca}^{2+}$ channels are not well established. This is particularly true for $\mathrm{LVA} \mathrm{Ca}^{2+}$ channels.

Single-channel recordings from guinea pigs suggest that T-type channels are particularly abundant on hippocampal CA3 pyramidal neurons, as compared with neurons from area CA1 or the dentate gyrus (Fisher et al., 1990). There are several ideas for how T-type channels could contribute to CA3 cellular physiology. One possible role is to provide a signal for weak synaptic input. CA3 neurons must integrate excitatory inputs from three anatomically distinct inputs that impinge at restricted regions of the apical dendrites. Dendritic LVA Ca ${ }^{2+}$ channels could electrically boost weak synapses (Magee and Johnston, 1995a), or they could produce a signal that provides for local, biochemical synaptic integration (Markram and Sakmann,

Received April 18, 1996; revised June 17, 1996; accepted June 18, 1996.

This work was supported by National Institutes of Health Grants MH10473 (R.A.), NS11535, MH44754, and MH48432 (D.J.)

Correspondence should be addressed to Dr. Robert B. Avery, Division of Neuroscience, Baylor College of Medicine, One Baylor Plaza, Houston, TX 77030.

Copyright (C) 1996 Society for Neuroscience $0270-6474 / 96 / 165567-16 \$ 05.00 / 0$
1994; Eilers et al., 1995; Magee et al., 1995). Another possible role for LVA channels is to contribute to the depolarizing envelope that underlies neuronal burst firing (Jahnsen and Llinas, 1984; Destexhe et al., 1996). CA3 cells show a high propensity for burst firing, and this behavior has voltage and $\mathrm{Ca}^{2+}$ requirements that could be satisfied by LVA Ca ${ }^{2+}$ channels (Hablitz and Johnston, 1981).

One reason that it has proved difficult to determine functional roles for LVA channels has been the lack of selective antagonists. Several drugs block T-type channels, but the quality of the blockade is quite variable across different cell types. In different cells, T-type channels also vary in their voltage dependence and kinetics. Therefore, to constrain and test hypotheses about how these channels contribute to specific cellular functions, it is necessary to characterize them in the neurons of interest.

We made whole-cell recordings from acutely isolated rat CA3 pyramidal neurons using physiological concentrations of $\mathrm{Ca}^{2+}$. We find that there are two distinct components to the LVA current. One current component is carried by T-type channels, and here we report the pharmacological profile and voltage dependence of the T-type current in CA3 cells. Further, we conclude that at least one other type of $\mathrm{Ca}^{2+}$ channel, which is sensitive to dihydropyridines, can be activated by a subthreshold stimulus near the resting potential. By definition, these channels should also be considered members of the LVA group.

\section{MATERIALS AND METHODS}

Cell preparation. Transverse hippocampal slices $500 \mu \mathrm{M}$ thick were cut from rats 7-14 d old in ice-cold, oxygenated dissecting saline (see Solu- 
tions). Slices were incubated in a solution in which papain $(10 \mathrm{U} / \mathrm{ml}$, Worthington, Freehold, NJ), cysteine (5 mM), EDTA (1 mM), and mercaptoethanol $(0.5 \mathrm{~mm})$ were added to $5 \mathrm{ml}$ of the dissecting saline. The incubation occurred for $30 \mathrm{~min}$ at $37^{\circ} \mathrm{C}$ with oxygen flowing over the solution surface. Slices were rinsed with $1 \mathrm{mg} / \mathrm{ml}$ bovine serum albumin (BSA) and transferred to a room temperature holding chamber in which $1 \mathrm{~mm} \mathrm{CaCl}$ had been added to the dissecting saline. As needed, two slices were removed from the holding chamber and the CA3 region dissected out in $1 \mathrm{mg} / \mathrm{ml} \mathrm{BSA}$. Cells were isolated by gently triturating the tissue through a series of four or five fire-polished Pasteur pipettes. The diameter of the smallest pipette was $\sim 250 \mu \mathrm{m}$. The resulting suspension was plated on a clean coverslip and allowed to settle for $5 \mathrm{~min}$, at which time the dissecting saline was gradually replaced with the recording solution.

Recordings. Patch pipettes were pulled from borosilicate glass (Drummond, Broomall, PA) on a two-stage vertical puller (Adams \& List, Westbury, NY) and coated with SYLGARD. The resistance of the electrode in the bath was 2-5 M 2 . Cells were visualized by using an inverted microscope (Zeiss) equipped with Hoffman modulation optics. Target cells had pyramidal-shaped somata with few or no short processes. Cells were patch-clamped with an Axopatch 1-C (Axon Instruments, Foster City, CA). Most current records were analog-filtered at $2 \mathrm{kHz}$, digitized between 1 and $5 \mathrm{kHz}$, and digitally filtered off-line at $1 \mathrm{kHz}$. Tail currents, however, were filtered at $5 \mathrm{kHz}$ and digitized at $20 \mathrm{kHz}$. Voltage commands were adjusted for tip potentials $(-8 \mathrm{mV}$ for the Tris-based saline; $-5 \mathrm{mV}$ for the TEA-MeSO${ }_{3}$ saline). The series resistance and cell capacitance were estimated by measuring the transient current in response to fast $5 \mathrm{mV}$ hyperpolarizing steps and by observing the value of the series resistance and whole-cell capacitance adjustments on the amplifier. Both methods yielded similar values. The average series resistance was $8.6 \pm 0.3 \mathrm{M} \Omega$, and the average capacitance was $22.7 \pm 1.0 \mathrm{pF}$. Series resistance was typically compensated to $75 \%$. Depolarizing test pulses were usually delivered once every $15 \mathrm{sec}$, and records were leaksubtracted off-line. The leak current was estimated by averaging a series of $10 \mathrm{mV}$ hyperpolarizing pulses ending $2 \mathrm{sec}$ before the test pulse. Cells had a mean input resistance of $1.6 \mathrm{G} \Omega$. The cell was positioned in the outlet stream of a multi-inlet microperfusion pipette, which allowed exchange of the solution bathing the cell within a few seconds. For all drug applications, the control saline included the drug vehicle. For example, the control saline for nimodipine included $0.1 \% \mathrm{EtOH}$, and most toxin experiments included $0.1 \%$ BSA in the control bath. Cells were used within $5 \mathrm{hr}$ after dissection, and the most robust recordings usually came from cells isolated near the beginning of this time frame.

Nonlinear functions were fit to the data using DISCRETE (Provencher, 1976) or NONLIN (Michael Johnson, Charlottesville, VA).

Solutions. The dissecting saline included (in mM): NaPIPES 110, $\mathrm{NaCl}$ 20, $\mathrm{KCl} 3, \mathrm{MgCl}_{2}$ 2, dextrose 10, and kynurenic acid 1, pH 7.4, 300 mOsm. The standard external recording saline included (in $\mathrm{mM}$ ): $\mathrm{CaCl}_{2} 2, \mathrm{MgCl}_{2}$ 1.5, TEA-Cl 160, CsCl 5, 3,4 DAP 0.1, HEPES 10, and TTX $1 \mu \mathrm{M}, \mathrm{pH} 7.4$, $300 \mathrm{mOsm}$. For most cells, the pipette solution included (in $\mathrm{mM}$ ): Tris base 28, Tris- $\mathrm{PO}_{4} 70$, TEA-Cl 40, $\mathrm{MgCl}_{2}$ 5, BAPTA 5, and EGTA 5. The tip was filled with this solution; then the pipette was backfilled with the same solution plus an ATP-regenerating system composed of Tris-ATP 4, Tris-GTP 0.3, Tris-phosphocreatine 14, creatine phosphokinase $50 \mathrm{U} / \mathrm{ml}$, and leupeptin 0.1, pH 7.3, 300 mOsm. A few recordings used the following pipette saline: TEA- $\mathrm{MeSO}_{3} 115, \mathrm{MgCl}_{2}$ 5, BAPTA 5, EGTA 5,

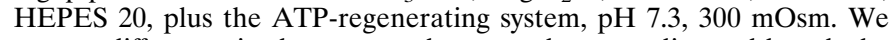
saw no difference in the currents between the two salines, although the recordings were more stable using the Tris-based saline.

Drugs. Nimodipine and D600 were purchased from Research Biochemicals (Natick, MA); $\omega$-agatoxin-IVa, $\omega$-conotoxin-GVIA, and $\omega$-conotoxin-MVIIC from American Peptide (Sunnyvale, CA); BayK8644 from Calbiochem (La Jolla, CA); calciseptine from Alomone Labs (Jerusalem, Israel). $\omega$-Grammotoxin-SIA was the generous gift of Rick Lampe from Zeneca Pharmaceuticals (Wilmington, DE). CsCl was obtained from Aldrich Chemicals (Milwaukee, WI) and TEA-Cl from Kodak (Rochester, NY) or Pfaltz-Bauer (New Hyde Park, NY). All other drugs were purchased from Sigma (St. Louis, MO).

\section{RESULTS}

\section{Whole-cell CA3 $\mathrm{Ca}^{2+}$ currents}

This study had two major goals: to identify the types of $\mathrm{Ca}^{2+}$ channels that could be activated by subthreshold stimulation and to determine the usefulness (potency and selectivity) of blockers of these channels. Because we wanted to avoid shifts in the apparent voltage dependence attributable to high divalent concentrations and because we wanted to make our results directly transferrable to physiologic studies, we used $\mathrm{Ca}^{2+}$ at a physiologic concentration $(2 \mathrm{~mm})$ as the charge carrier. Figure 1 shows $\mathrm{Ca}^{2+}$ currents evoked by $600 \mathrm{msec}$ depolarizations from two different holding potentials. In Figure $1 A$ currents were elicited from a holding potential of $-80 \mathrm{mV}$, corresponding to the total activatable current. At all test potentials the current displayed a prominent inactivating component. When the cell was held at $-50 \mathrm{mV}$ to isolate HVA channels, currents were considerably smaller, and the inactivating phase was much less pronounced (Fig. 1B). Presumably, this difference resulted from the steady-state inactivation of some $\mathrm{Ca}^{2+}$ channels at $-50 \mathrm{mV}$. We always held the cell at the holding potential for $>15 \mathrm{sec}$ before each depolarizing test pulse. Our leak-subtraction protocol assumed no standing $\mathrm{Ca}^{2+}$ current. At $-50 \mathrm{mV}$, this assumption is almost certainly incorrect, because we could evoke currents persisting for several seconds with depolarizing commands to $-50 \mathrm{mV}$. This would mean that, from a holding potential of $-50 \mathrm{mV}$, we probably underestimated the amplitude of the evoked current. The current-voltage $(I-V)$ relations for this cell are shown in Figure $1 C$. The peak of the evoked current is plotted as a function of the test potential for holding potentials of -80 and $-50 \mathrm{mV}$. From a holding potential of $-80 \mathrm{mV}$, the $I-V$ curve showed a prominent shoulder at negative potentials, indicating channel activation at low voltages. On average, the maximum amplitude of current evoked from -80 $\mathrm{mV}$ was $413 \mathrm{pA}$ and occurred at $-8 \mathrm{mV}$. The peak of the $I-V$ curve from a holding potential of $-50 \mathrm{mV}$ averaged $224 \mathrm{pA}$ and occurred at $-9 \mathrm{mV}(n=13)$. Current amplitudes were small, probably owing to three factors: (1) cells lacked processes, reducing the surface area, (2) cells were from young animals, and (3) currents were recorded with $2 \mathrm{mM} \mathrm{Ca}^{2+}$. Even within the narrow age range that we used (7-14 d), the amplitude of the HVA current was larger in cells from older animals. Near $14 \mathrm{~d}$, the HVA current was often large enough to obscure the shoulder because of LVA channels.

Long depolarizations to evoke LVA currents revealed two kinetically distinct components: one inactivating and one noninactivating (Fig. $1 D$, top trace). The inactivating phase of the current was best fit by the sum of two exponentials. The faster exponential had a time constant of $59 \mathrm{msec}(n=26)$. The slower time constant averaged $271 \mathrm{msec}$ but was extremely variable. A reliable fit would probably require steps longer than $600 \mathrm{msec}$, although the small amplitude of this term would still make it difficult. The LVA current did not completely inactivate, and current persisted even for depolarizations lasting several seconds (Fig. 1D, bottom trace).

Switching the charge carrier from $\mathrm{Ca}^{2+}$ to equimolar $\mathrm{Ba}^{2+}$ reduced the peak of the LVA current but enhanced the sustained component. This meant a much smaller transient current. The HVA current was also larger in $\mathrm{Ba}^{2+}$ (compared with $\mathrm{Ca}^{2+}$, in 2 mM Ba ${ }^{2+}$; LVA transient $66 \%$, LVA sustained $113 \%, n=4$; HVA $120 \%, n=6$; data not shown). To control for less charge screening with $\mathrm{Ba}^{2+}$, we repeated the experiment with $3.5 \mathrm{~mm} \mathrm{Ba}{ }^{2+}$. Although the currents were larger, the results were qualitiatively similar $(n=4)$. The differential response of the LVA components suggested that different channel types could underlie the two components. However, we could not exclude the possibility that the gating of a single channel type was altered in $\mathrm{Ba}^{2+}$.

We sought to determine if the two components result from the activation of the same or different types of $\mathrm{Ca}^{2+}$ channel. We 
A Total current

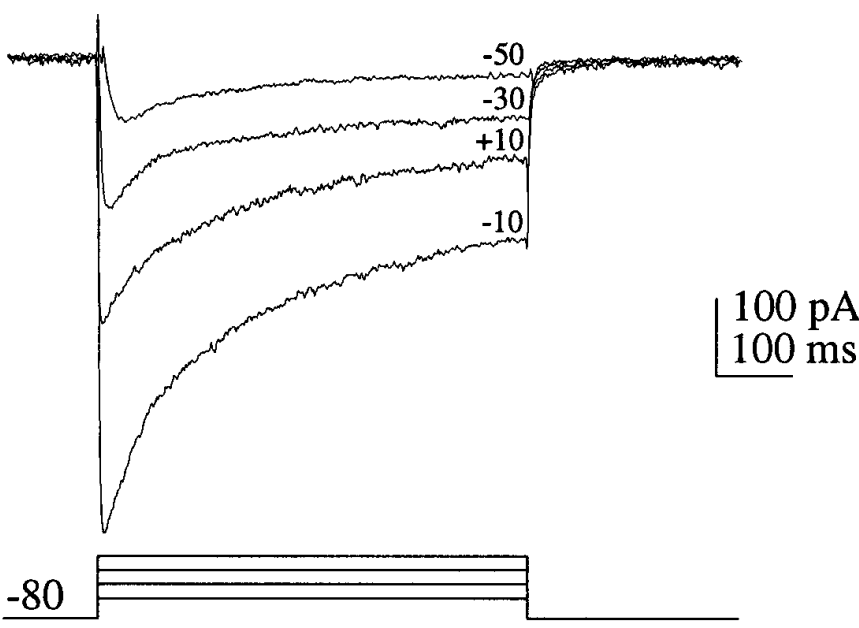

$\underline{-50}$

D

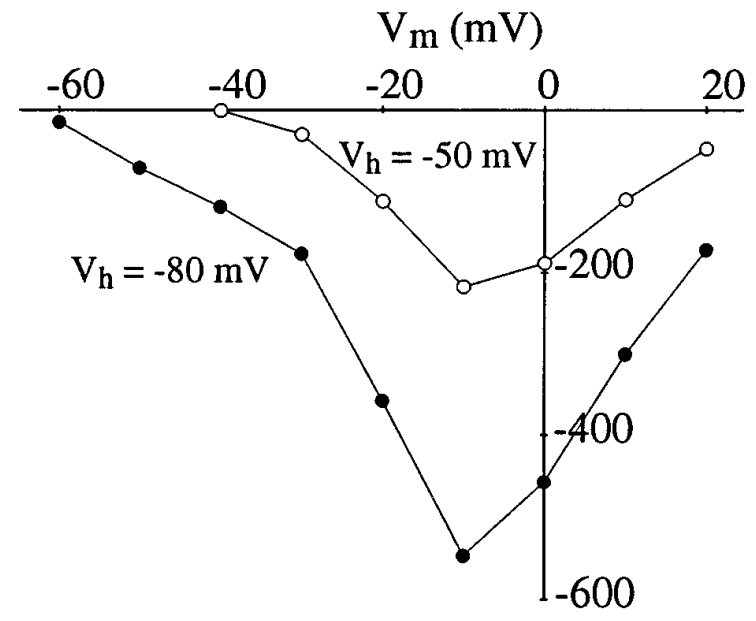

$\mathrm{I}(\mathrm{pA})$
B HVA current

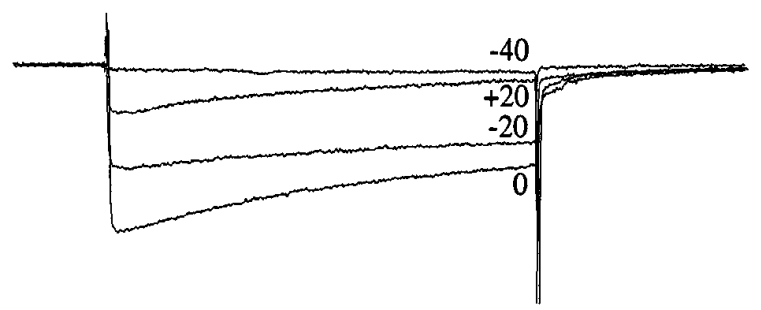

Figure 1. $\mathrm{Ca}^{2+}$ currents in CA3 pyramidal neurons. $A$, Currents elicited from a holding potential of $-80 \mathrm{mV}$. Currents had a prominent inactivating component. $B$, Currents elicited from a holding potential of $-50 \mathrm{mV}$ were smaller and showed much less inactivation during $600 \mathrm{msec}$ steps. $C$, $I-V$ plot for cell shown in $A$. The peak of the current is plotted as a function of the test potential for holding potentials of $-80 \mathrm{mV}(\mathbf{O})$ and $-50 \mathrm{mV}(O)$. Note the shoulder at negative potentials, indicating activation of LVA channels. On average, the maximum amplitude of current evoked from $-80 \mathrm{mV}$ was 413 $\mathrm{pA}$ and occurred at $-8 \mathrm{mV}$. The peak of the $I-V$ from a holding potential of $-50 \mathrm{mV}$ averaged $224 \mathrm{pA}$ and occurred at $-9 \mathrm{mV}(n=13)$. $D$, Steps to $-50 \mathrm{mV}$ elicited an LVA current with two components: transient and sustained. The decay during the transient phase could be best fit with two exponentials. The faster term had an average decay time constant of $59 \mathrm{msec}$. The second term averaged 217 msec but was quite variable. The bottom trace shows the sustained current persisting throughout a $3 \mathrm{sec}$ depolarization.

differentiated between these two possibilities by comparing the pharmacological profile of the LVA current components.

\section{Strategy for measuring current components}

To test the selectivity of blockers of LVA channels, we established a protocol to measure drug effects on LVA and HVA channels within the same cell. We functionally defined LVA channels as those channels that could be activated by a subthreshold stimulus.
Because the threshold for action-potential generation in hippocampal pyramidal cells is positive to $-50 \mathrm{mV}$, we set this as the cut-off for LVA channel activation. Consequently, LVA currents were evoked by holding at $-80 \mathrm{mV}$ and stepping to $-50 \mathrm{mV}$ for 600 msecs (Fig. 2A). To compare the pharmacology of the two LVA components, we further subdivided the LVA current and measured the inactivating and noninactivating phases. The noninactivating current was measured as the amplitude of the current 
A

LVA

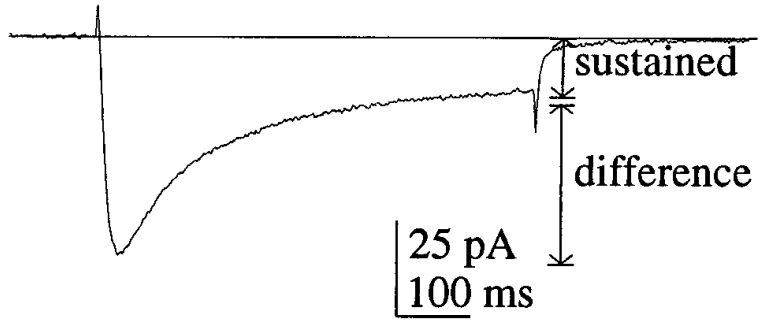

$-50$

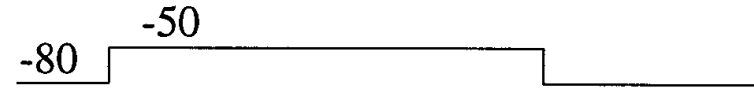

C

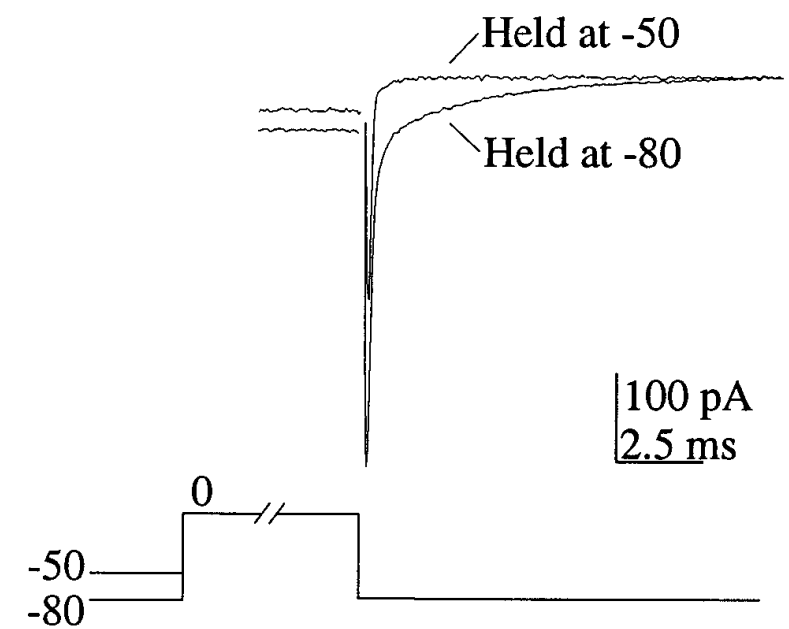

B

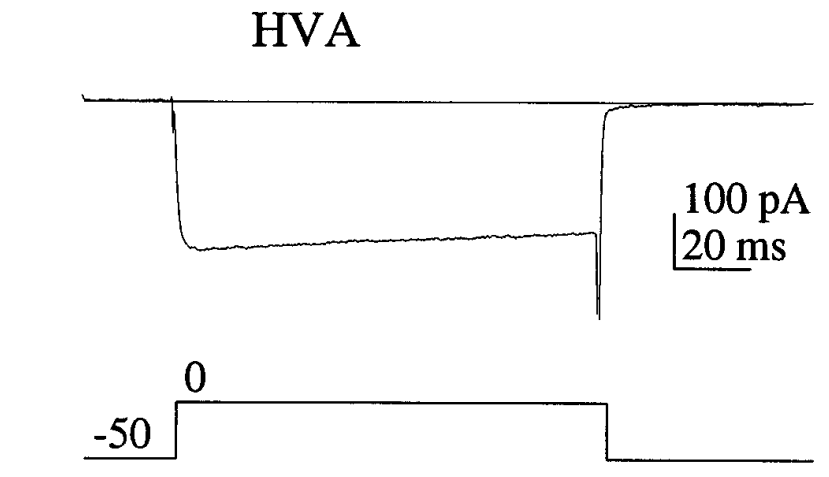

D

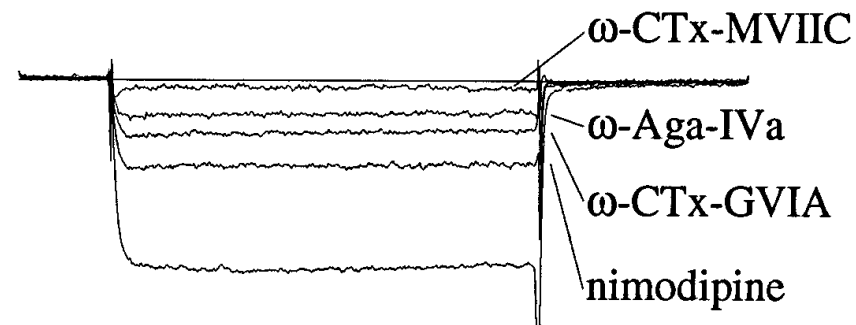

$25 \mathrm{pA}$

$20 \mathrm{~ms}$

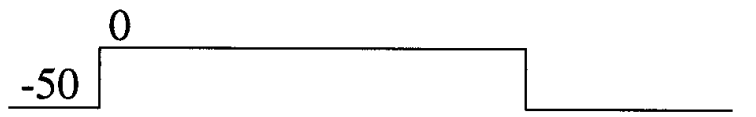

Figure 2. Strategy for measuring components of the $\mathrm{Ca}^{2+}$ current. $A$, LVA currents were evoked by holding at $-80 \mathrm{mV}$ and depolarizing to $-50 \mathrm{mV}$. The noninactivating current was measured as the amplitude of the current remaining at the end of a 600 msec step. This was called the sustained component. The amplitude of the inactivating component was estimated by taking the difference between the peak of the LVA current and the sustained current. This was called the difference component. The mean amplitude of the difference component was $34 \pm 19 \mathrm{pA}$, and the mean amplitude of the sustained component was $23 \pm 11 \mathrm{pA}(n=68)$. $B$. HVA currents were isolated by holding at $-50 \mathrm{mV}$ and stepping to $0 \mathrm{mV}$. The peak of the HVA current averaged $224 \pm 125 \mathrm{pA}(n=63)$. $C$, Tail currents upon repolarizing to $-80 \mathrm{mV}$. Cells were held at either $-50 \mathrm{or}-80 \mathrm{mV}$, stepped to $0 \mathrm{mV}$ for $30 \mathrm{msec}$, and then repolarized to $-80 \mathrm{mV}$. When held at $-50 \mathrm{mV}$, the amplitude of the slow component averaged $2.3 \%$ of the total tail amplitude $(n=7)$, indicating that T-type channels do not contribute significantly to the measure of HVA current. The first $200 \mu$ sec of repolarization has been blanked out. $D$, Pharmacology of the HVA current. Sequential applications of nimodipine, $\omega$-conotoxin-GVIA + nimodipine, $\omega$-agatoxin-IVA + nimodipine, and $\omega$-conotoxin-MVIIC + nimodipine are indicated. When adjusted for the estimated current rundown, the average block of each of these antagonists was $41 \%$ for nimodipine $(10 \mu \mathrm{M}), 28 \%$ for $\omega$-CTx-GVIA $(5 \mu \mathrm{M}), 15 \%$ for $\omega$-AgaTx-IVA (200 nM), and $8 \%$ for $\omega$-CTx-MVIIC (10 $\mu \mathrm{M})$, with $7 \%$ resistant to all blockers $(n=3)$.

remaining at the end of a 600 msec step. We defined this as the sustained component, and it was calculated by averaging the current amplitude from 550 to $600 \mathrm{msec}$. The amplitude of the inactivating component was estimated by taking the difference between the peak of the LVA current and the sustained current. We called this the difference component. Cells were included in the analysis only if both LVA components had control values $>10$ $\mathrm{pA}$. The mean amplitude of the difference component was $34 \pm$ $19 \mathrm{pA}$, and the mean amplitude of the sustained component was $23 \pm 11 \mathrm{pA}(n=68)$. To isolate HVA currents, we gave $120 \mathrm{msec}$ steps from -50 to $0 \mathrm{mV}$. We measured the peak of the HVA current, which averaged $224 \pm 125 \mathrm{pA}(n=63)$. Only cells that had HVA currents $>100$ pA were used for measurements.

The rationale for evoking HVA currents from a holding potential of $-50 \mathrm{mV}$ was that T-type channels should be inactivated at this potential (Mogul and Fox, 1991). To verify that T-type channels were not contaminating our measure of HVA currents, we performed the experiment shown in Figure $2 C$. Cells were held at $-80 \mathrm{mV}$, stepped to $0 \mathrm{mV}$ for $30 \mathrm{msec}$, and then repolarized to $-80 \mathrm{mV}$. Because T-type channels have much slower deactivation kinetics than other $\mathrm{Ca}^{2+}$ channels (Armstrong and Matteson, 1985), their activation will be revealed by a slow component of the 
tail current. Such a slow component is prominent in the $-80 \mathrm{mV}$ tail current of Figure $2 C$. We then repeated the experiment from a holding potential of $-50 \mathrm{mV}$. The slow component of the tail was much reduced when the current was elicited from a holding potential of $-50 \mathrm{mV}$, indicating that the T-type channels were largely inactivated at this potential. The tail currents were fit with the sum of two exponentials $\left(\bar{\tau}_{\text {fast }}=0.27 \mathrm{msec}, \bar{\tau}_{\text {slow }}=3.21 \mathrm{msec}\right)$ to estimate the amplitude of the slow-tail component. When held at $-50 \mathrm{mV}$, the amplitude of the slow component averaged $2.3 \%$ $(n=7)$ of the total tail amplitude. This indicates that most of the T-type channels were inactivated at equilibrium at $-50 \mathrm{mV}$. We conclude that the small fraction of T-channels activatable from $-50 \mathrm{mV}$ provided minimal contamination of HVA current measurements.

Because we ultimately wanted to use the HVA assay to test the specificity of LVA blockers, we also wanted to insure that our protocol to elicit HVA currents recruited all of the known types of HVA channels in CA3 neurons. We used common antagonists of HVA channels to test for the activation of pharmacologically defined HVA channels. HVA blockers were applied serially until the block by each agent reached a steady state (5-10 min). Figure $2 D$ shows the effects on the HVA current of sequential applications of nimodipine, $\omega$-conotoxin-GVIA + nimodipine, $\omega$-agatoxinIVA + nimodipine, and $\omega$-conotoxin-MVIIC + nimodipine. We estimated the rate of rundown that would have taken place in the absence of the toxins by measuring the slope of the current amplitude over time during control recordings. This slope was extrapolated linearly during the application of the three toxins. At the end of the $\omega$-CTx-MVIIC application (25-30 min after $\omega$-CTxGVIA was applied), we would predict the HVA current to have $\sim 60 \%$ of its control amplitude. When adjusted for the estimated current rundown, the average sequential block of each of these antagonists was $41 \%$ for nimodipine $(10 \mu \mathrm{M}), 28 \%$ for $\omega$-CTxGVIA $(5 \mu \mathrm{M}), 15 \%$ for $\omega$-AgaTx-IVA (200 nM), and $8 \%$ for $\omega$-CTx-MVIIC $(10 \mu \mathrm{M})$, with $7 \%$ resistant to all blockers $(n=3)$. The combination of nimodipine $(10 \mu \mathrm{M})+\omega$-CTx-MVIIC $(10$ $\mu \mathrm{M})$ blocked $87 \%$ of the HVA current $(n=5$; data not shown). We conclude that steps from -50 to $0 \mathrm{mV}$ elicited a composite current in which all of the pharmacologically defined hippocampal HVA channels were represented (McDonough et al., 1996).

\section{$\mathbf{C d}^{2+}$ was less effective at blocking LVA currents}

At higher concentrations cadmium $\left(\mathrm{Cd}^{2+}\right)$ is a nonselective $\mathrm{Ca}^{2+}$ channel blocker, but at lower concentrations LVA currents have shown less susceptibility than HVA currents (Ozawa et al., 1989; Mogul and Fox, 1991).

The effect of different concentrations of $\mathrm{Cd}^{2+}$ on $\mathrm{Ca}^{2+}$ currents is shown in Figure 3. Part $A$ compares current traces taken in the presence of control, 10, 100, and $500 \mu \mathrm{M} \mathrm{Cd}^{2+}$. At each concentration, $\mathrm{Cd}^{2+}$ demonstrated a stronger block of the HVA current. For example, some LVA current was spared at concentrations sufficient to eliminate the HVA current (see the $100 \mu \mathrm{M}$ traces). The two components of the LVA current shared a similar sensitivity to $\mathrm{Cd}^{2+}$. In Figure $3 B$, the amplitudes of the LVA difference, LVA sustained, and HVA currents are plotted over time. Time zero is the onset of whole-cell recording (break-in). $\mathrm{Ca}^{2+}$ currents tended to run up for $\sim 10 \mathrm{~min}$ and then run down over the rest of the experiment. We typically waited 15 min after breaking-in before starting drug applications. The rate of rundown differed among the current components. HVA currents ran down the fastest, whereas the LVA difference component ran down slowest. On average, the HVA current ran down to half of its original amplitude (determined 15 min after break-in) over the next $\approx 2000 \mathrm{sec}$. In comparison, the LVA sustained and LVA difference components ran down to half of their original amplitude over $\approx 3800$ and $5800 \mathrm{sec}$, respectively. To measure drug effects, the amplitude of the control current was extrapolated to the time of the drug measurement. Examples of extrapolated baselines are shown in the $100 \mu \mathrm{M}$ exposure of Figure $3 B$. Figure $3 C$ summarizes the $\mathrm{Cd}^{2+}$ dose-response of the measured components of the $\mathrm{Ca}^{2+}$ current. To compare drug effects across cells, the amplitude of the current in the presence of the drug was expressed as a percentage of its extrapolated baseline value. Thus, throughout the paper, a smaller number means less resistant current (greater block). The HVA current was more sensitive to $\mathrm{Cd}^{2+}$, with an $\mathrm{IC}_{50}<1 \mu \mathrm{M}$. The LVA difference and LVA sustained components both had an $\mathrm{IC}_{50} \approx 100 \mu \mathrm{M}$.

Although the block was less, we cannot conclude that $\mathrm{Cd}^{2+}$ has a lower affinity for LVA channels. Because HVA currents were assayed at $0 \mathrm{mV}$ but LVA currents were measured at $-50 \mathrm{mV}$, the differential effects of $\mathrm{Cd}^{2+}$ could be attributable, at least in part, to voltage dependence of the $\mathrm{Cd}^{2+}$ block (Brown et al., 1983; Byerly et al., 1984). In support of this interpretation, we observed an initial transient in the HVA records with 1 and $10 \mu \mathrm{M} \mathrm{Cd}^{2+}$ (see arrow in the $10 \mu \mathrm{M}$ HVA trace in Fig. $3 A$ ). These transients suggest that it takes a few milliseconds for the $\mathrm{Cd}^{2+}$ block to equilibrate to the new membrane potential. This is important, because it indicates that $\mathrm{Cd}^{2+}$ may not be as selective for HVA over LVA channels as is commonly believed. $\mathrm{Cd}^{2+}$ may be less effective for all channels at the negative potentials at which LVA channels are usually isolated.

\section{$\mathrm{Ni}^{2+}$ reduced the inactivating component of the LVA current}

Nickel $\left(\mathrm{Ni}^{2+}\right)$ is the most commonly used antagonist for T-type channels and has been used to probe the physiological function of T-type channels (Hagiwara et al., 1988). In hippocampal neurons, however, the reported potency of $\mathrm{Ni}^{2+}$ is quite variable, ranging from almost complete block at $25 \mu \mathrm{M}$ (Ozawa et al., 1989) to an $\mathrm{IC}_{50} \approx 230 \mu \mathrm{M}$ (Takahashi and Akaike, 1991). Further, the selectivity of $\mathrm{Ni}^{2+}$ for T-type channels over other types is not well established.

The effect of different concentrations of $\mathrm{Ni}^{2+}$ on $\mathrm{Ca}^{2+}$ currents is shown in Figure 4. Part $A$ compares current traces taken in the presence of control, 10, 50, and $500 \mu \mathrm{M} \mathrm{Ni}^{2+}$. At a given concentration, $\mathrm{Ni}^{2+}$ was most effective at blocking the inactivating component of the LVA current (for example, see the $50 \mu \mathrm{M}$ trace). Part $B$ plots the amplitudes of the LVA difference (top), LVA sustained (middle), and HVA (bottom) currents over time. Figure $4 C$ summarizes the $\mathrm{Ni}^{2+}$ dose-response of the measured components of the $\mathrm{Ca}^{2+}$ current. The LVA difference component was most sensitive, with $10 \mu \mathrm{M}$ $<\mathrm{IC}_{50}<50 \mu \mathrm{M}$. The sustained LVA component and the HVA current were less sensitive. Both had a $100 \mu \mathrm{M}<\mathrm{IC}_{50}<500 \mu \mathrm{M}$. Concentrations of $\mathrm{Ni}^{2+}$ sufficient to eliminate the transient component $(>100 \mu \mathrm{M})$ markedly reduced other components of the $\mathrm{Ca}^{2+}$ current. We conclude that $\mathrm{Ni}^{2+}$ preferentially blocks channels underlying the LVA difference component, although other channel types may also be inhibited by $\mathrm{Ni}^{2+}$.

\section{Amiloride, phenytoin, and ethosuximide affected the LVA current differently}

Amiloride blocks T-type channels in hippocampal neurons (Takahashi et al., 1989; Mogul and Fox, 1991), and it has been used to suggest a role for T-type channels in mossy-fiber LTP, in which 

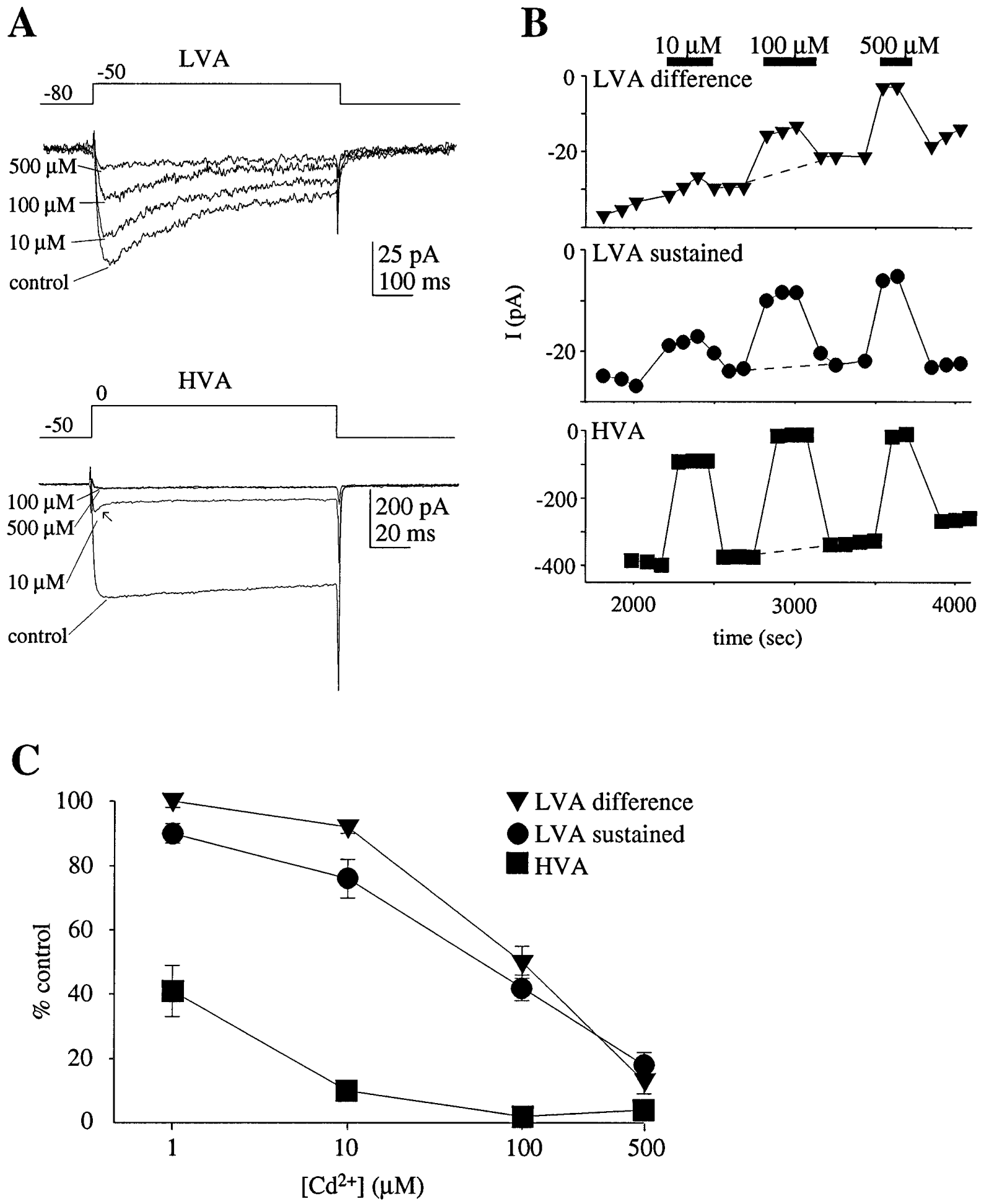

Figure 3. $\mathrm{Cd}^{2+}$ was less effective at blocking LVA currents. $A$, Current traces taken in the presence of control, 10, 100, and $500 \mu \mathrm{M} \mathrm{Cd}{ }^{2+}$. The top set of traces shows LVA currents. Bottom traces show the effects of the same applications on HVA currents. For the HVA current, the 100 and $500 \mu \mathrm{M}$ traces are indistinguishable. Note the initial transient in the $10 \mu \mathrm{M}$ trace (arrow), indicating time-dependent equilibration of the block to the new membrane potential. $B$, Time course of current component amplitudes from the same cell as in $A$. The amplitude of the LVA difference component (top), LVA sustained component (middle), and HVA peak (bottom) are plotted as a function of time, with 0 corresponding to the start of whole-cell recording. Dotted lines during the $100 \mu \mathrm{M}$ exposure demonstrate how the baseline was extrapolated for measurements. $C$, Dose-response relationship for $\mathrm{Cd}^{2+}$ for the measured current components. Current amplitudes are normalized to the estimated baseline amplitude. The percent of the control amplitude of the LVA difference ( $\mathbf{\nabla})$, LVA sustained ( $\bullet$ ), and HVA components $(\mathbf{\square})$ are plotted as a function of $\mathrm{Cd}^{2+}$ concentration. Error bars in all figures represent SEM. The HVA current was much more sensitive $\left(\mathrm{IC}_{50}<1 \mu \mathrm{M}\right)$ to $\mathrm{Cd}^{2+}$ than the two LVA current components, which were equally sensitive $\left(\mathrm{IC}_{50} \approx 100 \mu \mathrm{M}\right)$. The amplitude of the current (as a percent of the control value) in the presence of $\mathrm{Cd}^{2+}$ was $1 \mu \mathrm{M}$ : LVA difference 106\%, LVA sustained 95\% $(n=6)$, HVA 44\% $(n=6)$; $10 \mu \mathrm{M}$ : LVA difference $97 \%$, LVA sustained 78\% $(n=8)$, HVA 10\% $(n=9) ; 100 \mu \mathrm{M}$ : LVA difference 50\%, LVA sustained 42\% ( $n=8)$, HVA $2 \%(n=9) ; 500 \mu \mathrm{M}:$ LVA difference $12 \%$, LVA sustained $22 \%(n=8)$, HVA $4 \%(n=10)$. 
A
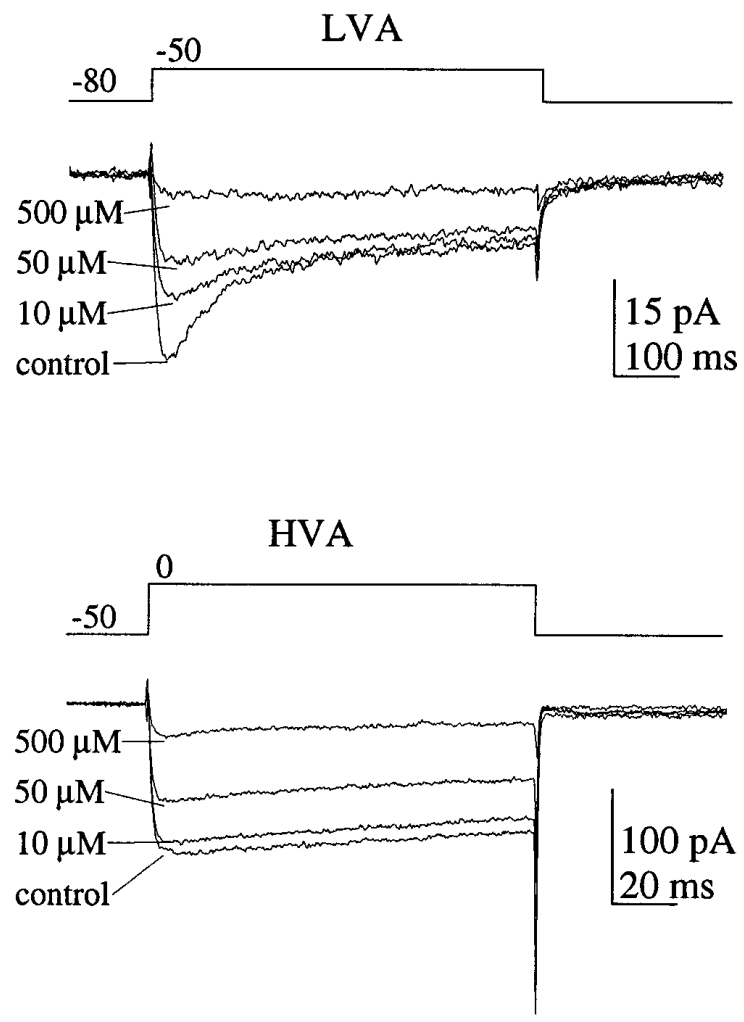

B

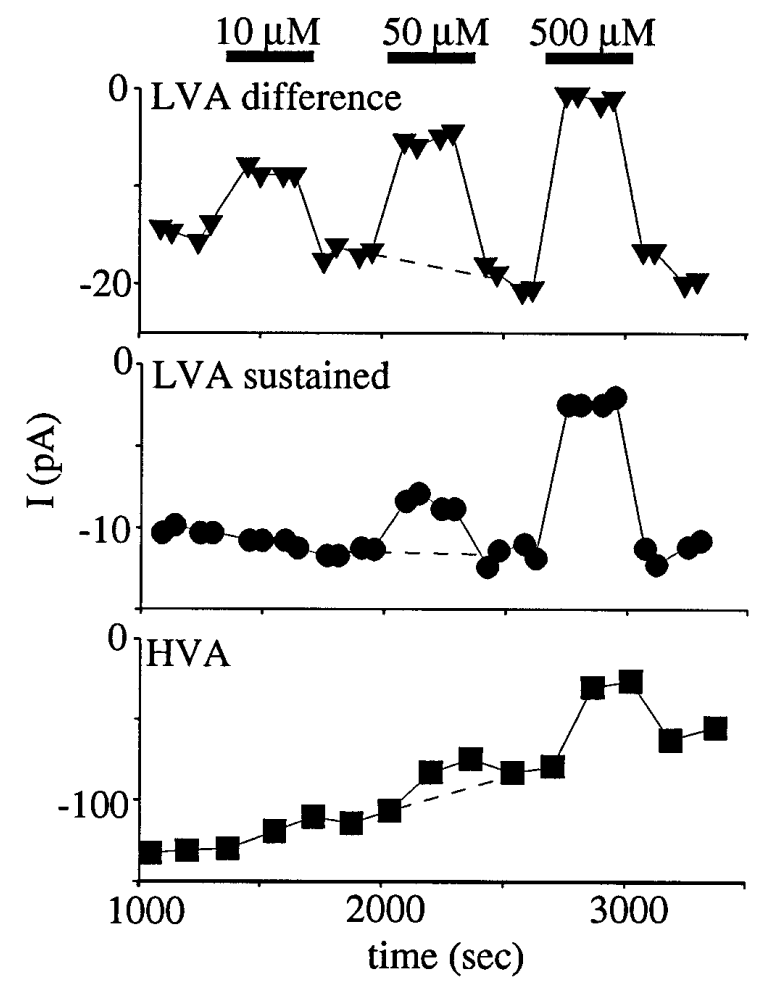

C

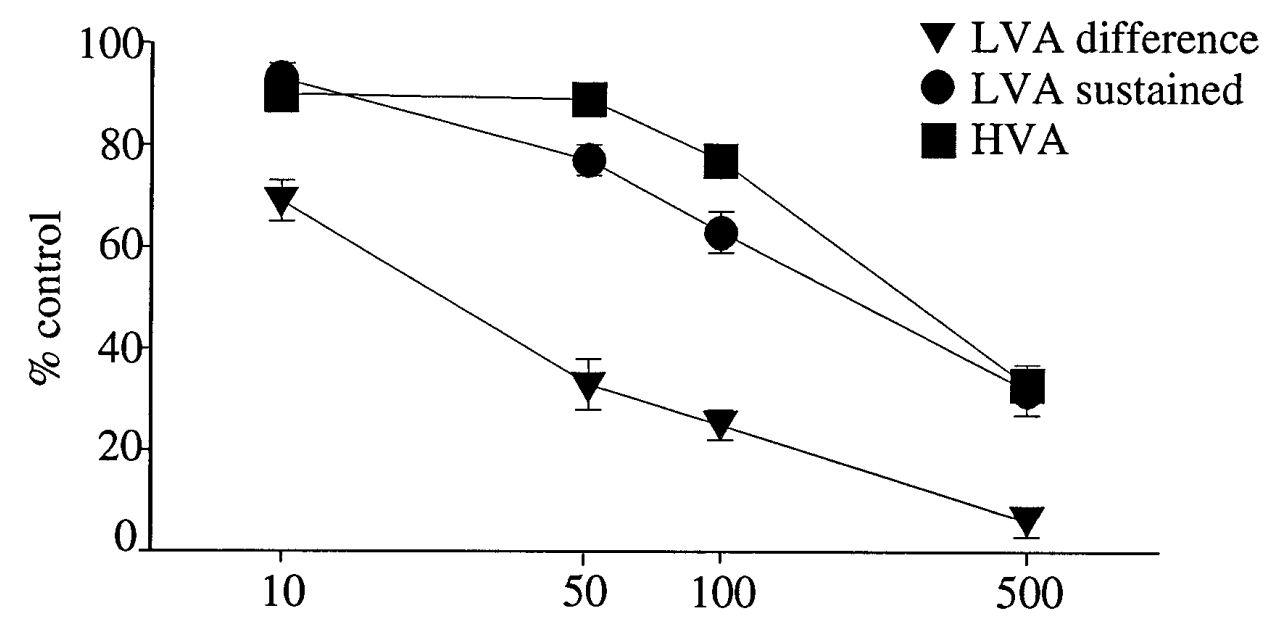

$\left[\mathrm{Ni}^{2+}\right](\mu \mathrm{M})$

Figure 4. $\mathrm{Ni}^{2+}$ preferentially inhibited the LVA difference component. $A$, Current traces taken in the presence of control, 10, 50, and 500 $\mu \mathrm{M} \mathrm{Ni}{ }^{2+}$. The top set of traces shows LVA currents. Bottom traces show the effects of the same applications on $\mathrm{HVA}$ currents. At a given concentration, $\mathrm{Ni}^{2+}$ was most effective at blocking the transient component of the LVA current (for example, see the $50 \mu \mathrm{M}$ trace). $B$, Time course of current component amplitudes from the same cell in $A$. The amplitude of the LVA difference component (top), LVA sustained component (middle), and HVA peak (bottom) are plotted as a function of time. Dotted lines during the $50 \mu \mathrm{M}$ exposure demonstrate how the baseline was extrapolated for measurements. $C$, Dose-response relationship for $\mathrm{Ni}^{2+}$ for the measured current components. Effects on LVA difference $(\boldsymbol{\nabla})$, LVA sustained $(\bullet)$, and HVA components $(\boldsymbol{\square})$ are plotted as a function of $\mathrm{Ni}^{2+}$ concentration. The LVA difference component was more sensitive than the other current components, with $10 \mu \mathrm{M}<\mathrm{IC}_{50}<50 \mu \mathrm{M}$. The LVA sustained and HVA components shared similar sensitivities to $\mathrm{Ni}^{2+}$, with $100 \mu \mathrm{M}<\mathrm{IC}_{50}<500 \mu \mathrm{M}$. The amplitude of the current (as a percent of the control value) in the presence of $\mathrm{Ni}^{2+}$ was $10 \mu \mathrm{M}$ : LVA difference 69\%, LVA sustained 93\% $(n=6)$, HVA 90\% $(n=8)$; $50 \mu \mathrm{M}$ : LVA difference 33\%, LVA sustained 77\% $(n=6)$, HVA 89\% $(n=5)$; $100 \mu \mathrm{M}$ : LVA difference 25\%, LVA sustained 63\% $(n=6)$, HVA 77\% $(n=7)$; $500 \mu \mathrm{M}:$ LVA difference $6 \%$, LVA sustained $32 \%(n=6)$, HVA $33 \%(n=6)$. 
CA3 cells are the postsynaptic neurons for mossy fibers (Kamiya, 1989). However, the selectivity of amiloride for T-type over other channels is unclear. The effect of amiloride on $\mathrm{Ca}^{2+}$ currents is shown in Figure $5 A$. Similar to $\mathrm{Ni}^{2+}$, amiloride $(250 \mu \mathrm{M})$ most strongly blocked the transient component of the LVA current. The LVA sustained component and the HVA current were less sensitive. Summary data for amiloride are presented in the graph in Figure $5 D$. Each of the current components is represented by its own bar, the height of which indicates the amplitude of the current as a percentage of the control amplitude (shorter bars mean greater block). Amiloride at $250 \mu \mathrm{M}$ inhibited approximately half of the LVA difference current with less inhibition of the LVA sustained component and the HVA current. When amiloride $(250 \mu \mathrm{M})$ and $\mathrm{Ni}^{2+}(50 \mu \mathrm{M})$ were coapplied, the effect on the transient current was less than additive, suggesting that $\mathrm{Ni}^{2+}$ and amiloride are blocking the same channels. Coapplication also produced a greater block of the other current components.

Phenytoin (diphenylhydantoin) inhibits LVA currents in cultured hippocampal neurons (Yaari et al., 1987) and isolated CA1 cells (Takahashi et al., 1989). Phenytoin showed a much different profile from amiloride (Fig. $5 B$ ). The strongest effect of phenytoin was on the LVA sustained current, although all current components were affected by $100 \mu \mathrm{M}$ phenytoin. Summary data for phenytoin are presented in Figure $5 D$. Because phenytoin differentially blocks the LVA components, one interpretation is that different channel types underlie the two LVA current components. However, we cannot rule out activity-dependent block by phenytoin, making it more effective at the end of a $600 \mathrm{msec}$ step than at the beginning. Activity- and voltage-dependent actions of phenytoin are well described for $\mathrm{Na}^{+}$channels (Matsuki et al., 1984; Kuo and Bean, 1994).

Ethosuximide partially blocks LVA currents in thalamic neurons, and this action is postulated to underlie its anticonvulsant action in thalamic seizures (Coulter et al., 1989). In hippocampal CA3 neurons, all components of the $\mathrm{Ca}^{2+}$ current were insensitive to ethosuximide at concentrations of $250 \mu \mathrm{M}$ or $1 \mathrm{~mm}$ (Fig. 5C).

\section{Voltage dependence of T-type $\mathrm{Ca}^{2+}$ channel inactivation}

The pharmacological profile of the inactivating LVA current suggests that it results from the openings of T-type $\mathrm{Ca}^{2+}$ channels. We wondered whether the sustained LVA current could be explained by a persistent activation of T-type channels. Steady-state inactivation of T-type channels was determined by measuring the amplitude of the difference component as a function of holding potential. Figure $6 A$ illustrates a typical experiment. Steps to -50 $\mathrm{mV}$ were given from holding potentials ranging from -60 to -120 $\mathrm{mV}$. The amplitude of the inactivating component was measured as a function of holding potential and normalized to the maximum amplitude. The normalized values were averaged for each holding potential (plotted in Fig. $6 C ; n=8$ cells) and fit to the Boltzmann function: $G / G_{\max }=1 /\left[1+\exp \left(\left(V-V_{1 / 2}\right) / k\right)\right]$, in which $V_{1 / 2}$ is the half-maximum voltage and $k$ is the slope factor. The best fit was achieved with $V_{1 / 2}=-80$ and $k=-6.4 \mathrm{mV}$.

The resulting curve suggests few T-type channels are activatable near steady state at $-50 \mathrm{mV}$. Given the relative insensitivity of the LVA sustained component to $\mathrm{Ni}^{2+}$ and amiloride, it seems unlikely that the LVA sustained current results solely from the persistent activation of T-type channels. We hypothesized that at least one other type of $\mathrm{Ca}^{2+}$ channel must contribute to the LVA sustained current. To test this hypothesis, we assayed the effects on LVA currents of agents that affect other types of $\mathrm{Ca}^{2+}$ channels.

\section{Dihydropyridines modulated the LVA sustained current}

While performing the experiments shown in Figure $2 D$, we observed that nimodipine, a dihydropyridine (DHP) L-type channel antagonist, reduced the amplitude of the LVA-sustained component. Therefore, we further investigated the effects of DHPs on CA3 $\mathrm{Ca}^{2+}$ currents. We used $10 \mu \mathrm{M}$ nimodipine, because this is a saturating dose in hippocampal neurons (Eliot and Johnston, 1994) and because effects of nimodipine at this concentration are not voltage-dependent (Marchetti et al., 1995). As shown in Figure $7 A$, nimodipine inhibited the same current amplitude throughout the LVA step. This resulted in a reduction of the sustained component but no change in the difference component. Nimodipine also inhibited part of the composite HVA current, presumably that fraction carried by L-type channels. We should note that high concentrations of dihydropyridines can have nonspecific effects, even on $\mathrm{Na}^{+}$(Yatani and Brown, 1985) and $\mathrm{K}^{+}$ channels (Hume, 1985). Similar nonspecific effects on $\mathrm{Ca}^{2+}$ channels (Jones and Jacobs, 1990) would overestimate the contribution of L-type channels to the whole-cell current.

We postulated that DHP-sensitive channels contribute to the LVA-sustained current. One prediction is that BayK-8644, a DHP $\mathrm{Ca}^{2+}$ channel agonist, would potentiate the sustained current. Figure $7 B$ shows the effect of $1 \mu \mathrm{M}$ BayK-8644. BayK increased the amplitude of the sustained current but did not affect the inactivating component of the LVA current. BayK also had the expected effect on the HVA current: potentiation of the peak and slowing of the deactivation (tail) kinetics.

Population data for nimodipine and BayK-8644 are shown in Figure $7 C$. It is important to note that the LVA transient current was insensitive to nimodipine and BayK. In contrast, the LVAsustained component was modulated in parallel with the HVA current-reduced by nimodipine and enhanced by BayK. When coapplied, the block of nimodipine $(10 \mu \mathrm{M})$ and $\mathrm{Ni}^{2+}(100 \mu \mathrm{M})$ approximated the sum of their individual effects. This suggests that they are blocking separate types of channels. We conclude that activation of DHP-sensitive channels contributes to the sustained LVA current.

\section{Activation of nimodipine-sensitive current}

We determined the steady-state activation of the nimodipinesensitive current in CA3 neurons. In control saline, the sustained current was measured $120 \mathrm{msec}$ into the depolarization for step potentials from -70 to $+20 \mathrm{mV}$. The series was repeated in the presence of $10 \mu \mathrm{M}$ nimodipine and then repeated again after washing. Figure $8 A$ shows sample traces recorded at a test potential of $0 \mathrm{mV}$. The amplitude of the nimodipine-sensitive current was determined by subtracting the current amplitude in nimodipine from the average of the control and wash values for each step potential. The chord conductance was calculated by assuming a $\mathrm{Ca}^{2+}$ reversal potential extrapolated from the linear, positive slope region of the $I-V$ curve (usually from 0 to $+20 \mathrm{mV}$ ). This provided the most negative estimate of the reversal potential (range +25 to $+40 \mathrm{mV}$ ). We felt this was the most conservative approach, because an error in the negative direction will tend to shift the conductance curve more positive. The chord conductance at each potential was normalized to the maximum conductance. The normalized values were averaged for each step potential (plotted in Fig. $8 C ; n=6$ cells) and fit to the Boltzmann function. A single Boltzmann adequately fit the data, with optimal values of $V_{1 / 2}=-30 \mathrm{mV}$ and $k=6.0 \mathrm{mV}$. 


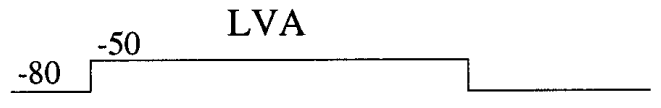

A amiloride $(250 \mu \mathrm{M})$

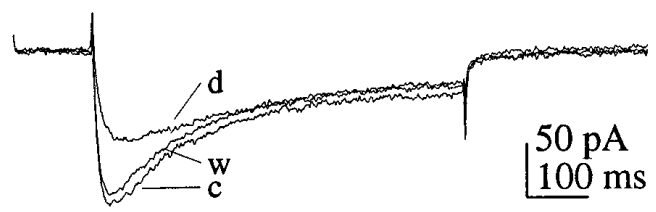

B phenytoin $(100 \mu \mathrm{M})$

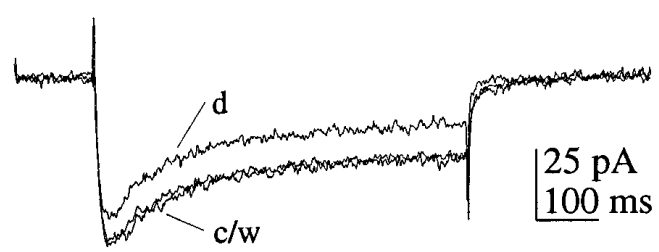

$(250 \mu \mathrm{M})$

C ethosuximide

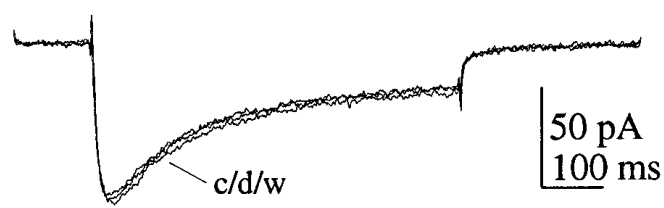

D

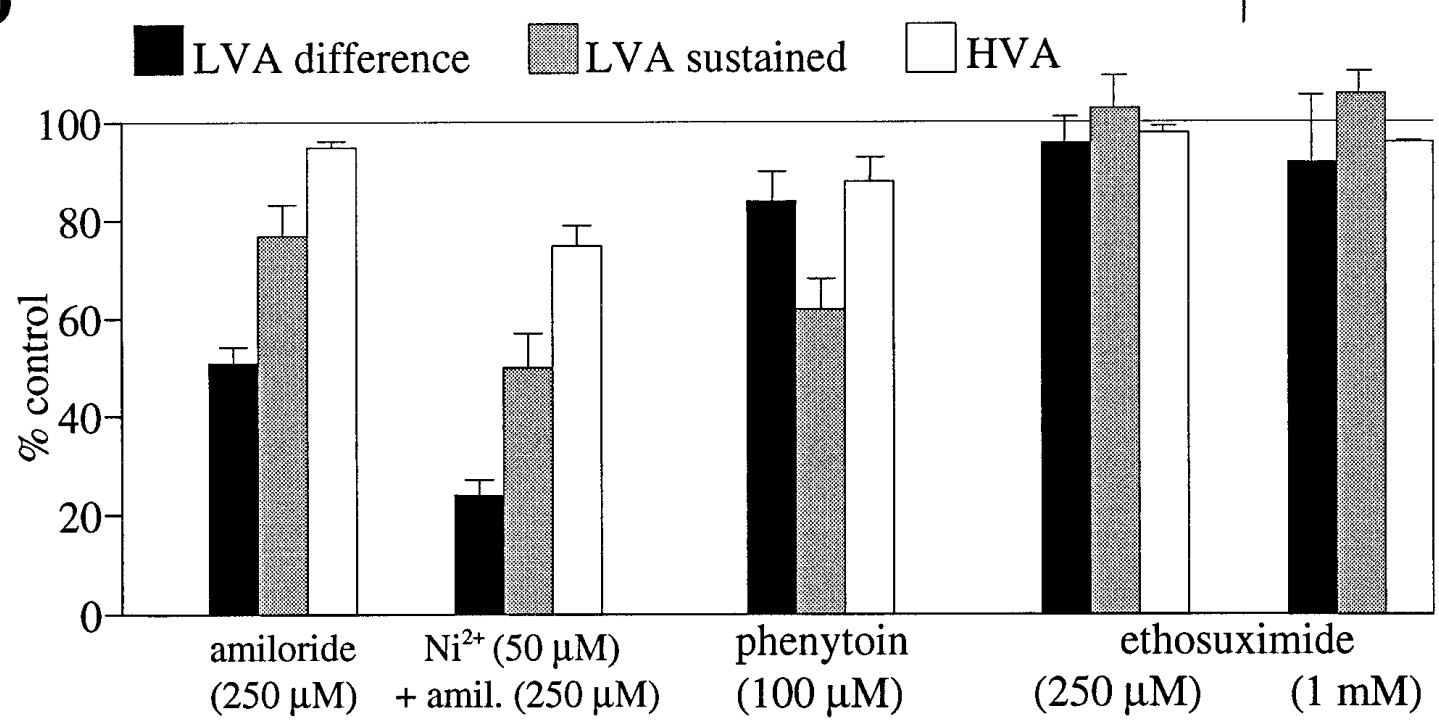

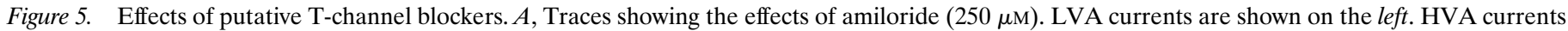

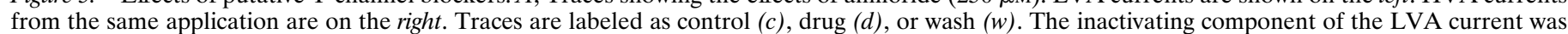

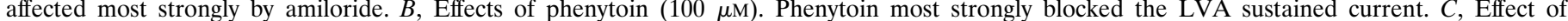

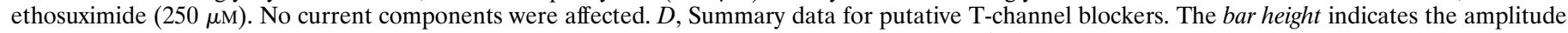

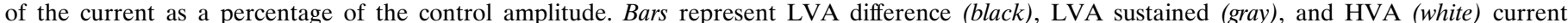

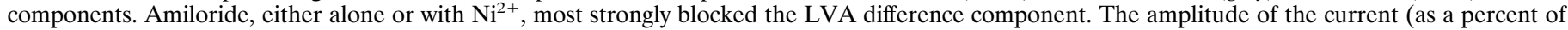

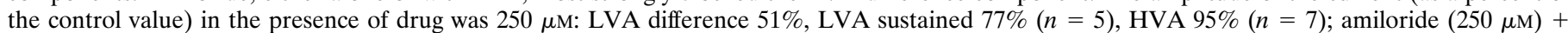

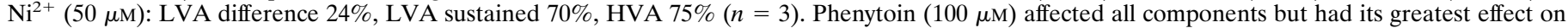

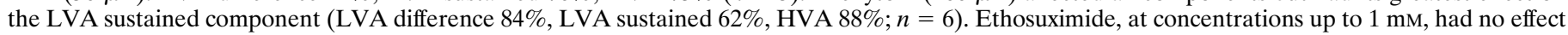

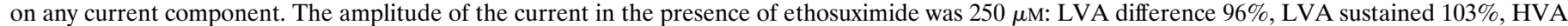
98\% $(n=3)$; 1 mM: LVA difference 92\%, LVA sustained 106\%, HVA 96\% $(n=3)$. 
A
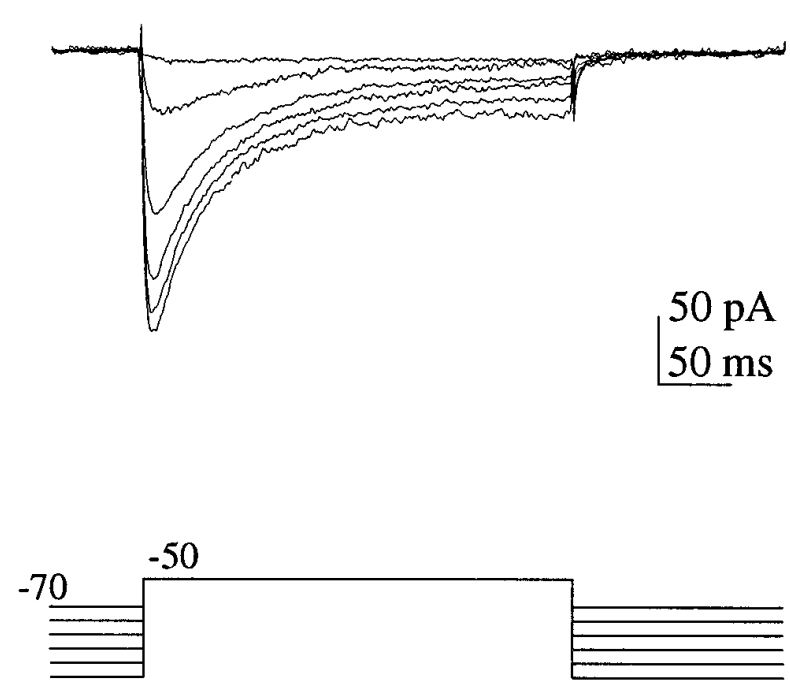

$-120$
B

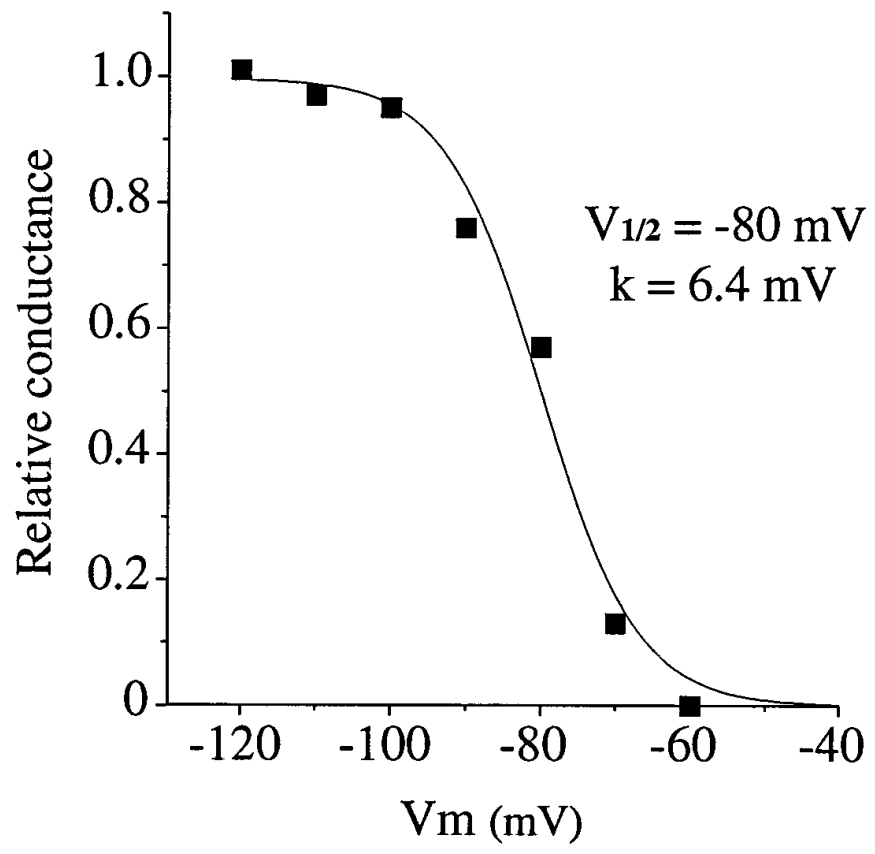

Figure 6. Steady-state inactivation of T-type $\mathrm{Ca}^{2+}$ channels. $A$, Traces showing the dependence of LVA currents on the holding potential. The membrane potential was stepped to $-50 \mathrm{mV}$ from holding potentials ranging from -70 to $-120 \mathrm{mV}$. The amplitude of the difference component increased steeply with holding potentials negative to $-70 \mathrm{mV}$. $B$, Steady-state inactivation curve. Steady-state inactivation was determined from experiments like that shown in $A$. The amplitude of the difference component of the LVA current was measured as a function of holding potential. The amplitude of the current was normalized to the maximum difference current. The symbols ( $\mathbf{\square})$ represent pooled data from eight cells. The curve is a least-squares fit to the Boltzmann function: $G / G_{\max }=1 /\left[1+\exp \left(\left(V-V_{1 / 2}\right) / k\right)\right]$, in which $V_{1 / 2}$ is the half-maximum voltage and $k$ is the slope factor. The best fit was achieved with $V_{1 / 2}=-80 \mathrm{mV}$ and $k=-6.4 \mathrm{mV}$.

This activation curve was surprisingly similar to that expected for T-type channels (Fig. 6C). One possible explanation is simply that nimodipine is blocking T-type channels. However, nimodipine did not affect the difference component of the LVA current (Fig. 7C). Additionally, we minimized contamination by T-type currents in the analysis by measuring the current amplitude 120 msec into the step pulse. Further, about $28 \%$ of the HVA current (assayed at $0 \mathrm{mV}$ ) is blocked by nimodipine. This current does not result from the activation of T-type channels, because it is evoked from a holding potential of $-50 \mathrm{mV}$. Therefore, nimodipine block of T-type channels is an unsatisfactory explanation for the activation at negative potentials that we recorded.

We also fit the sustained currents remaining in the presence of nimodipine. The peak of the $I-V$ of the nimodipine-resistant currents was about $10 \mathrm{mV}$ positive to the peak of the nimodipinesensitive current (see Fig. $8 B$ ). As shown in the dotted lines of Figure $8 C$, a Boltzmann fit to the nimodipine-resistant current reflected this shift, yielding a $V_{1 / 2}=-19 \mathrm{mV}$ and $k=6.3 \mathrm{mV}$. Activation of dihydropyridine-sensitive channels at potentials more negative than other HVA channels was first reported using $\mathrm{Ba}^{2+}$ in rat dorsal root ganglion neurons (Regan et al., 1991). We conclude that nimodipine-sensitive channels in CA3 pyramidal neurons are active at potentials more negative than other types of HVA channels.

\section{Toxins blocked the LVA sustained component}

We used $\mathrm{Ca}^{2+}$-channel toxins to further identify the types of channels responsible for the LVA sustained current. Calciseptine is a snake toxin that irreversibly antagonizes L-type $\mathrm{Ca}^{2+}$ currents without affecting N-type or T-type currents in dorsal root ganglion cells (de Weille et al., 1991). We used calciseptine to control for nonspecific, voltage-dependent, or activity-dependent effects of 10 $\mu \mathrm{M}$ nimodipine. As illustrated in Figure $9 A$, the LVA sustained component and the HVA current were partially blocked by $5 \mu \mathrm{M}$ calciseptine. Figure $9 D$ summarizes the effects of calciseptine. Similar to nimodipine, the toxin reduced the LVA sustained component and the HVA current but spared the LVA difference component. This result strengthens the suggestion that an L-type channel contributes to the sustained component. $\mathrm{Ca}^{2+}$ currents were more blocked strongly by nimodipine than by calciseptine, suggesting that $5 \mu \mathrm{M}$ is not a saturating dose of the toxin. We also tested the $\mathrm{Ca}^{2+}$-channel antagonist D600 (methoxyverapamil). At $100 \mu \mathrm{M}$, D600 blocked the measured components of the $\mathrm{Ca}^{2+}$ current equally well (LVA difference $42 \%$, LVA sustained $41 \%$, HVA $39 \%$; $n=4$; data not shown).

We used the snail toxin $\omega$-conotoxin-MVIIC to screen for contributions from N- or P-type channels. As shown in Figure 9B, $\omega$-conotoxin-MVIIC had no effect on either component of the LVA current, but the HVA current was markedly reduced. Summary data are presented in Figure $9 D$. The lack of effect on the LVA current indicates that $\omega$-CTx-MVIIC is specific for HVA channels and that $\mathrm{N}$-type and $\mathrm{P}$-type channels are not activated by a subthreshold stimulus.

Finally, we used the spider toxin $\omega$-grammotoxin-SIA ( $\omega$ GsTX). $\omega$-GsTx has an inhibitory profile similar to $\omega$-CTX-MVIIC (Piser et al., 1995), although it can block an additional component of $\mathrm{Ca}^{2+}$-mediated neurotransmitter release (Turner et al., 1995). 


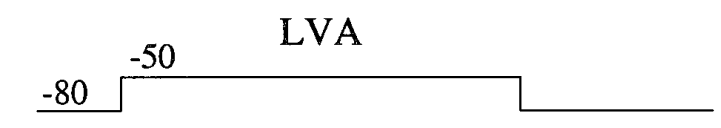

A nimodipine $(10 \mu \mathrm{M})$

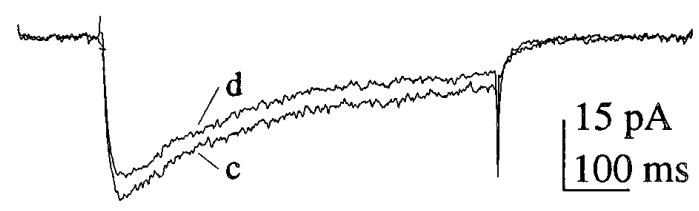

B $\operatorname{BayK} 8644(1 \mu \mathrm{M})$

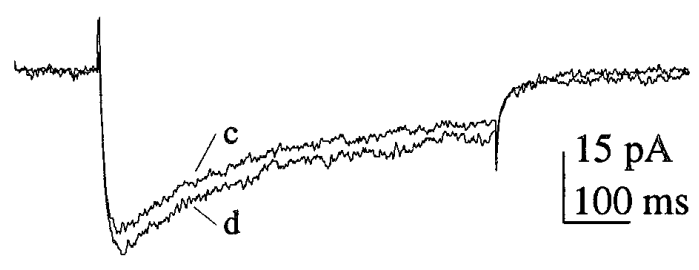

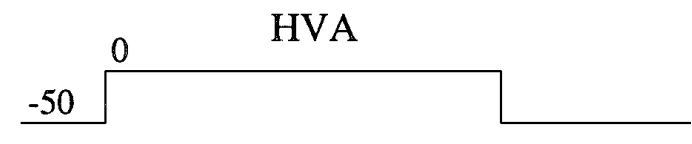
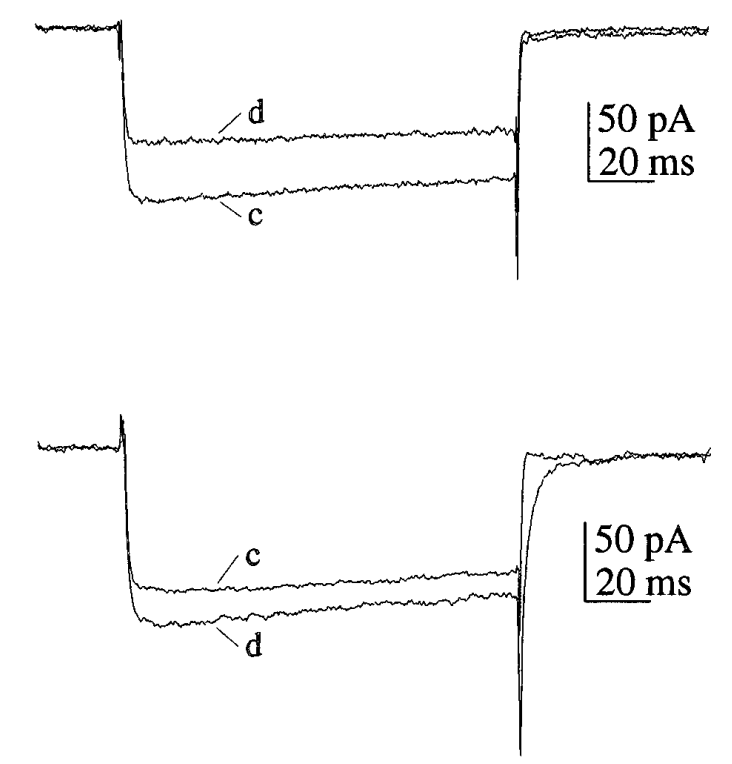

C

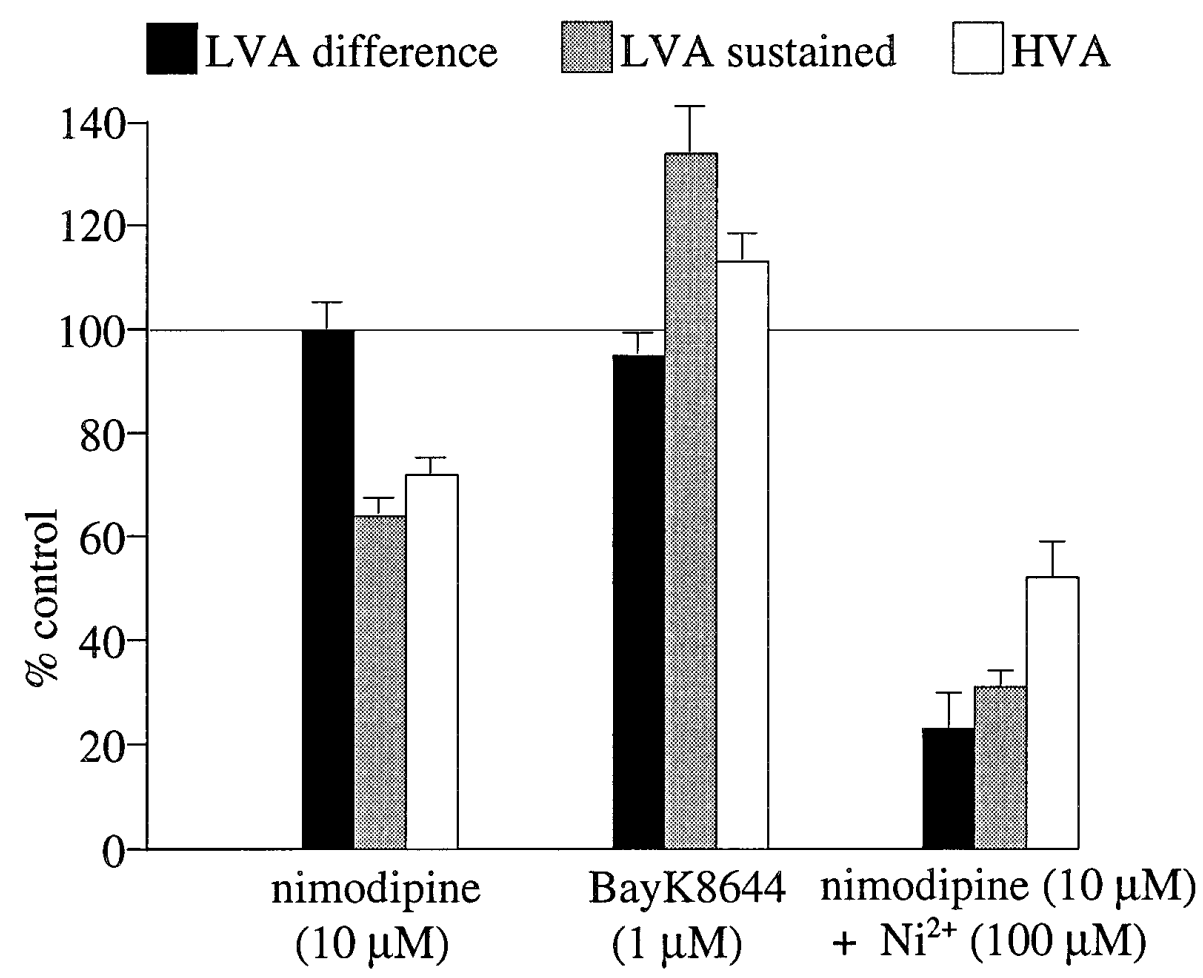

Figure 7. A, Traces showing the effects of nimodipine $(10 \mu \mathrm{M})$. LVA currents are shown on the left. HVA currents from the same application are on the right. Traces are labeled as control $(c)$ or drug $(d)$. Nimodipine partially inhibited the LVA sustained component without affecting the LVA difference component. The HVA current was also partially reduced. $B$, Effects of BayK-8644 $(1 \mu \mathrm{M})$. BayK-8644 potentiated the LVA sustained current and the HVA current, but the LVA difference current was insensitive. $C$, Summary data for nimodipine and BayK-8644. Amplitudes of each current component during the application are plotted as a fraction of their control values. DHPs had no effect on the LVA difference component, but the LVA sustained component was modulated similarly to the HVA current. Both were reduced by nimodipine and enhanced by BayK [10 $\mu \mathrm{M}$ nimodipine: LVA difference 100\%, LVA sustained 64\% $(n=8)$; HVA 72\% $(n=20)$; $1 \mu \mathrm{M}$ BayK-8644: LVA difference 95\%, LVA sustained 134\% $(n=3)$; HVA 113\%, $(n=6)]$. The block by coapplying $\mathrm{Ni}^{2+}(100 \mu \mathrm{M})$ and nimodipine $(10 \mu \mathrm{M})$ was nearly additive (when compared to their individual effects), indicating that they blocked different types of channels [LVA difference 23\%, LVA sustained $31 \%(n=4)$; HVA $52 \%(n=6)$ ]. 
A

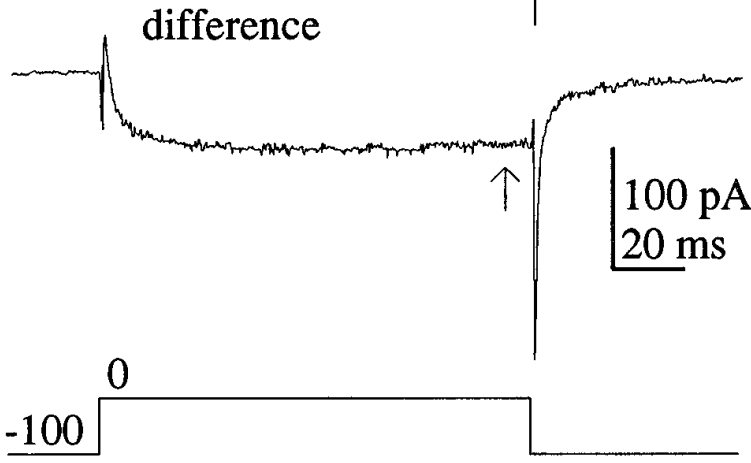

B

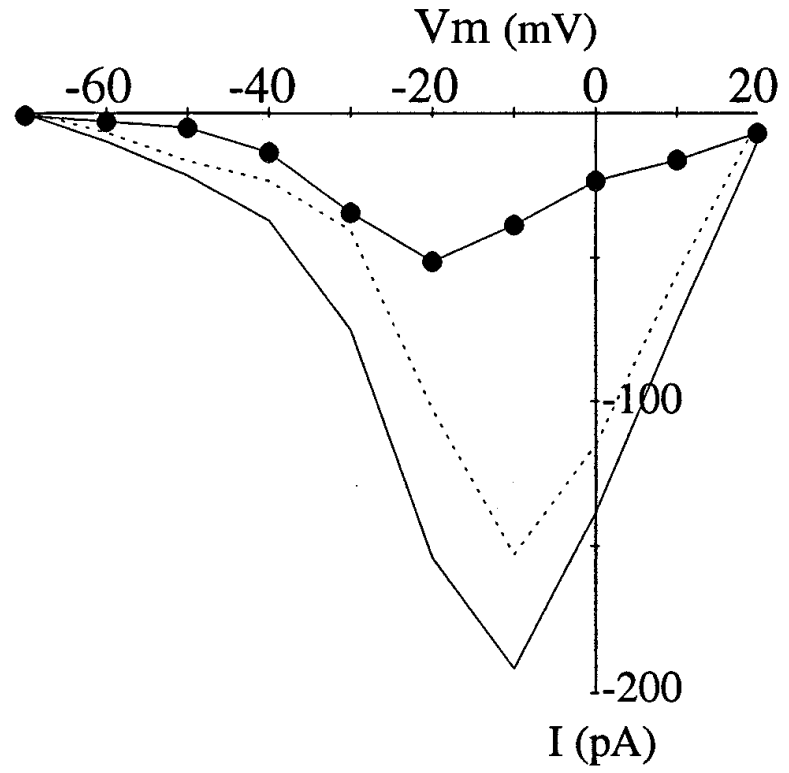

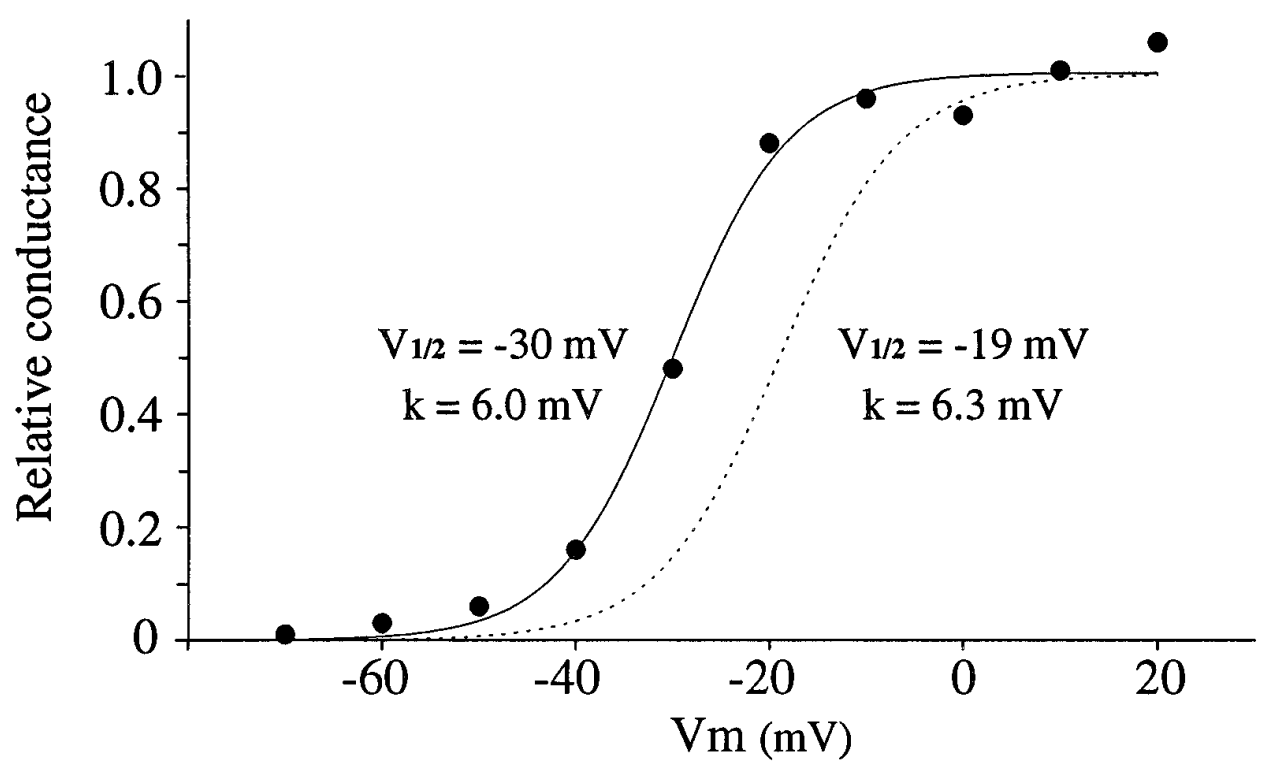

Figure 8. Activation of nimodipine-sensitive current. A, Example of data used to generate the plot in $C$. Top traces show currents recorded in control and nimodipine $(10 \mu \mathrm{M})$ with steps to $0 \mathrm{mV}$. Bottom trace is the difference of the top traces, representing the nimodipine-sensitive current. The amplitude of the nimodipine-sensitive current was determined for each test potential by measuring the amplitude of the difference current at 120 msec (arrows). $B$, $I-V$ relations for nimodipine-sensitive and insensitive currents in a single cell. As shown in $A$, cells were held at $-100 \mathrm{mV}$ and stepped to potentials between -70 and $+20 \mathrm{mV}$. The series was repeated in the presence of $10 \mu \mathrm{M}$ nimodipine and after several minutes of washing. The amplitude of the nimodipine-sensitive current was measured at each step potential by subtracting the amplitude of the current in nimodipine from the average of the control and wash currents. Solid line is the total current amplitude (control) at each test potential, measured at 120 msec. Dotted line is the current amplitude in the presence of $10 \mu \mathrm{M}$ nimodipine. Filled circles $(\bullet)$ represent the difference current (nimodipine-sensitive). $C$, Steady-state activation curve

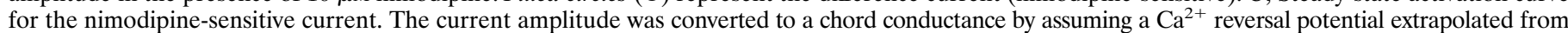
the linear, positive slope region of the $I-V$ curve (approximately $+25 \mathrm{mV}$ for this cell). The chord conductance at each potential was normalized to the maximum conductance, and the normalized values were averaged for each step potential. The symbols $(\bullet)$ represent pooled data from six cells. The solid line is a least-squares fit to the Boltzmann function with $V_{1 / 2}=-30 \mathrm{mV}$ and $k=6.0 \mathrm{mV}$. The dotted line is the least-squares fit for the sustained current resistant to nimodipine $\left(V_{1 / 2}=-19 \mathrm{mV}, k=6.3 \mathrm{mV}\right)$. 


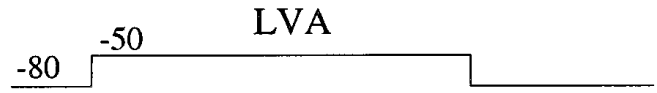

A calciseptine $(5 \mu \mathrm{M})$

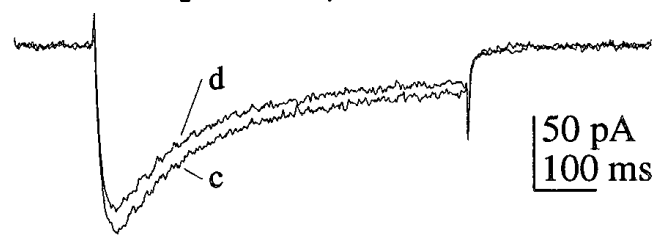

B $\operatorname{MVIIC}(10 \mu \mathrm{M})$

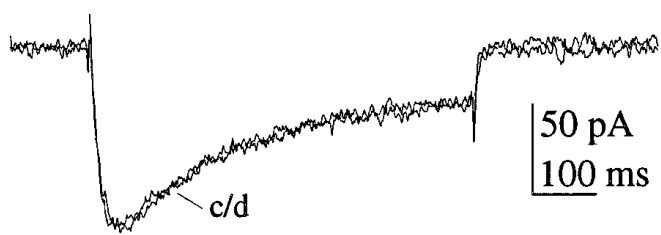

C GsTx SIA $(10 \mu \mathrm{M})$

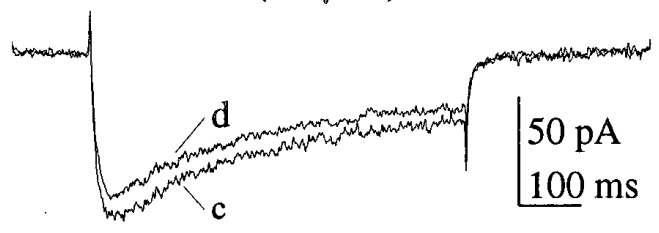

D

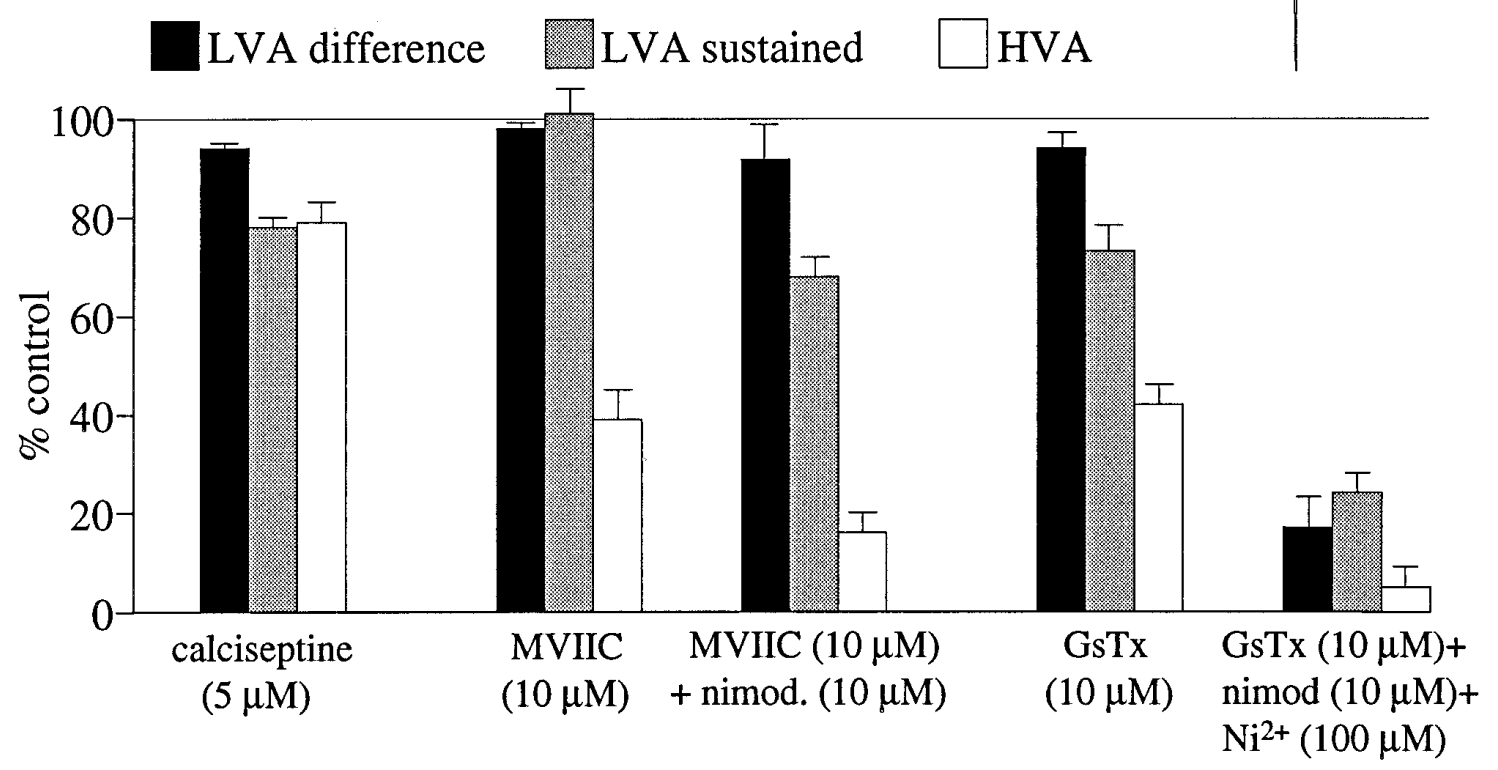

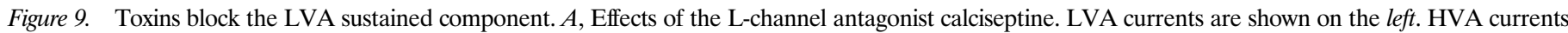
from the same application are on the right. Traces are labeled as control $(c)$ or drug $(d)$. Calciseptine $(5 \mu \mathrm{M})$ partially inhibited the LVA sustained and HVA currents but did not affect the LVA difference current. $B$, Effects of the nonspecific HVA antagonist $\omega$-conotoxin-MVIIC ( $\mu \mathrm{M})$. The LVA current was not affected, but the HVA current was strongly reduced. $C$, Effects of the HVA antagonist $\omega$-grammotoxin-SIA ( $\omega$-GsTx-SIA, $10 \mu \mathrm{M}$ ). The LVA sustained current was partially inhibited. The HVA current was strongly reduced. $D$, Summary data for three toxins. Calciseptine reduced the LVA sustained component (78\%, $n=4)$ and the HVA current $(79 \%, n=5)$ but spared the LVA difference component $(94 \%, n=4)$. $\omega$-CTx-MVIIC did not affect the LVA current (LVA difference $98 \%$, LVA sustained $101 \% ; n=7)$ but did reduce the HVA current $(39 \%, n=10)$. $\omega$-GsTx-SIA partially reduced the LVA sustained component $(74 \%, n=3)$ and LVA difference component $(84 \%, n=3)$. The HVA current was also reduced $(42 \%, n=3)$. The combination of $\omega$-GsTx-SIA $(10 \mu \mathrm{M})+$ nimodipine $(10 \mu \mathrm{M})+\mathrm{Ni}^{2+}(100 \mu \mathrm{M})$ strongly blocked all current components (LVA difference 17\%, LVA sustained 24\%, HVA 5\%; $n=3$ ). 
Table 1. Pharmacological differences of the LVA current components

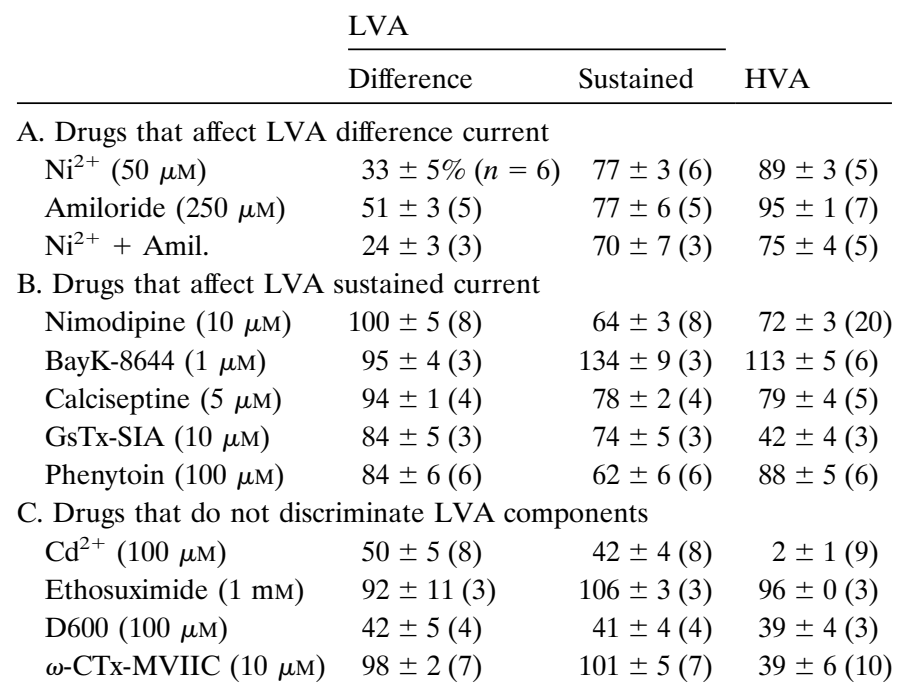

Drugs are grouped according to whether they preferentially inhibited the LVA difference component (A), the LVA sustained component (B), or did not discriminate between the two LVA components $(\mathrm{C})$. Current component amplitudes in the presence of each drug are expressed as a percentage of the control amplitude; mean $\pm \operatorname{SEM}(n)$.

In contrast to $\omega$-CTX-MVIIC, $10 \mu \mathrm{M} \omega$-GsTX reduced the LVA sustained component. It also strongly inhibited the HVA current. Summary data are presented in Figure 9D. This result suggests that $\omega$-CTx-MVIIC-resistant channels contribute to the LVA sustained current. Because $\omega$-GsTx does not block L-type channels, another channel type (not L-, N-, or P-type) may be active at low voltages. Coapplication of $\omega$-GsTx $(10 \mu \mathrm{M})$, nimodipine $(10 \mu \mathrm{M})$, and $\mathrm{Ni}^{2+}(100 \mu \mathrm{M})$ strongly inhibited each of the measured components of the $\mathrm{Ca}^{2+}$ current.

Table 1 summarizes the pharmacological results of this study. The differential pharmacology of the LVA current is emphasized by grouping drugs according to their selectivity for the LVA difference or sustained component.

\section{DISCUSSION}

We recorded LVA and $\mathrm{HVA} \mathrm{Ca}^{2+}$ currents in acutely isolated rat hippocampal CA3 pyramidal neurons. Using $2 \mathrm{mM} \mathrm{Ca}^{2+}$ as the charge carrier, we recorded two kinetically distinct components of the LVA current: inactivating and noninactivating. We measured the inactivating current as the difference component and the noninactivating current as the sustained component. We determined the pharmacological profile of the two components by using antagonists of LVA and HVA $\mathrm{Ca}^{2+}$ channels.

\section{T-type channels underlie the transient component}

The voltage dependence, kinetics, and pharmacology of the difference component indicate that it results from activation of T-type $\mathrm{Ca}^{2+}$ channels. T-type channels are abundant on CA3 neurons and would be expected to open with our stimulus to isolate LVA channels (Fisher et al., 1990). T-type channels undergo fast, voltage-dependent inactivation. At the potentials we studied, previously reported kinetics of inactivation are consistent with our measured decay time constant for the difference component (Takahashi et al., 1991; Thompson and Wong, 1991). Finally, the difference component was most susceptible to the commonly used T-channel blockers $\mathrm{Ni}^{2+}$ (Fox et al., 1987) and amiloride (Tang et al., 1988).

\section{Usefulness of T-channel blockers}

A major goal of this study was to test the usefulness of blockers of T-type $\mathrm{Ca}^{2+}$ channels. To use blockers to dissect the contribution of T-type channels to cellular physiology, it is important to know how much T-type channels can be inhibited without affecting other types of $\mathrm{Ca}^{2+}$ channels.

$\mathrm{Ni}^{2+}$ is the most commonly used T-channel antagonist. In CA3 cells, $50 \mu \mathrm{M} \mathrm{Ni}^{2+}$ blocked approximately two-thirds of the T-type current. However, even this concentration of $\mathrm{Ni}^{2+}$ had some effect on the HVA current, and higher concentrations markedly affected the HVA current. We conclude that concentrations of $\mathrm{Ni}^{2+}$ sufficient to eliminate T-type channels will significantly inhibit other $\mathrm{Ca}^{2+}$ channels as well. Even experiments using lower concentrations of $\mathrm{Ni}^{2+}(\leq 50 \mu \mathrm{M})$ should be interpreted with the understanding that other types of $\mathrm{Ca}^{2+}$ channels may be partly affected.

Results using amiloride lead to a similar conclusion. Amiloride $(250 \mu \mathrm{M})$ blocked approximately one-half of the T-type current with a small inhibition of the HVA current. Concentrations of amiloride sufficient to eliminate T-type channels certainly will affect other $\mathrm{Ca}^{2+}$ channels. Moreover, effects of amiloride are not restricted to $\mathrm{Ca}^{2+}$ channels. Indeed, amiloride is most well known as an inhibitor of membrane $\mathrm{Na}^{+}$flux (Palmer, 1984).

Phenytoin has been reported to selectively block T-type channels in cultured hippocampal neurons (Yaari et al., 1987). In our experiments, $100 \mu \mathrm{M}$ phenytoin was not selective for the difference component of the LVA current. In fact, the sustained component was blocked more strongly. Given the well described effects of phenytoin on hippocampal $\mathrm{Na}^{+}$channels (Kuo and Bean, 1994), it is unlikely to be useful as a selective antagonist for studies of T-type $\mathrm{Ca}^{2+}$ channel physiology.

Ethosuximide, at concentrations up to $1 \mathrm{~mm}$, did not affect CA3 $\mathrm{Ca}^{2+}$ currents. This contrasts with the thalamus, in which T-type channels are sensitive to ethosuximide (Coulter et al., 1989). It has been postulated that the anticonvulsant actions of ethosuximide in the thalamus result from inhibition of thalamic T-type channels. In this light, it is interesting that ethosuximide is ineffective against hippocampal seizures (Niedermeyer, 1990).

Overall, our results match well with the pharmacology of T-type channels in CA1 cells (Takahashi and Akaike, 1991; Thompson and Wong, 1991). This suggests that T-type channels may not vary much between CA3 and CA1 cells and that data from one cell type may be extrapolated to the other.

\section{Voltage dependence of T-type channels}

Our measurements of the voltage dependence of steady-state inactivation for T-type channels in CA3 neurons fit well with those published for CA1 neurons (Takahashi et al., 1991; Thompson and Wong, 1991; Magee and Johnston, 1995b), although they are difficult to reconcile with the inactivation at extremely negative potentials reported by Mogul and Fox (1991). Our results indicate that a small proportion of T-channels are available for activation at the resting membrane potential but that the curve is quite steep in the hyperpolarizing direction. This suggests that the magnitude of physiological T-type current may be influenced strongly by recent hyperpolarizing episodes (Magee et al., 1995).

\section{Different channels underlie the two LVA components}

The existence of two components to the LVA current raised two general possibilities. The noninactivating component may represent incomplete inactivation of the same channels carrying the transient component. Alternatively, separate channel types could underlie the two components. At least three lines of evidence 
suggest that more than one type of channel is activated by our subthreshold stimulus. (1) $\mathrm{Ni}^{2+}$ and amiloride were more effective in blocking the difference component than the sustained component. (2) The sustained current was modulated by dihydropyridines, but the difference component was not. (3) Calciseptine, $\omega$-GsTx-SIA, and phenytoin preferentially inhibited the sustained component.

Because the LVA sustained component is partially sensitive to $\mathrm{Ni}^{2+}$ and amiloride, we cannot exclude some contribution of T-type channels to the sustained LVA current. In cranial sensory neurons (Bossu and Feltz, 1986) and $\mathrm{GH}_{3}$ cells (Herrington and Lingle, 1992), T-type currents show two phases of inactivation, with the slower phase occurring on the order of seconds. If present in CA3 cells, such a mechanism could provide for residual T-type channel activation at $600 \mathrm{msec}$. Given the differences in the pharmacology of the two LVA components, however, persistent activation of T-type channels is inadequate to fully explain the noninactivating current.

Hence, T-type channels are not the only $\mathrm{Ca}^{2+}$ channels that warrant the designation "low-voltage activated." Rather, the LVA group comprises the T-type and at least one other type of $\mathrm{Ca}^{2+}$ channel.

\section{Channels underlying the sustained component}

Probably the most striking finding in this study was that the LVA current is sensitive to dihydropyridines. The sensitivity of the sustained current to DHPs and the toxin calciseptine indicate that L-type channels may be active at low voltages with physiologic concentrations of external $\mathrm{Ca}^{2+}$. We estimated the voltage dependence of activation of L-type channels by measuring the nimodipine-sensitive current. The largest amplitude of the nimodipine-sensitive current occurred at $-20 \mathrm{mV}$, with half-maximal activation at $-30 \mathrm{mV}$. This suggests a surprisingly negative range for activation of L-type channels in CA3 cells. The use of physiologic concentrations of $\mathrm{Ca}^{2+}$ in this study may have shifted the measured activation more negative, either by reduced charge screening or by direct effects on channel gating (Hille, 1992; Zhou and Jones, 1995). Such shifts can be especially pronounced for L-type channels, as has been shown in chromaffin cells (Artalejo et al., 1991). Further, we used a high concentration of nimodipine to overcome the voltage dependence of block. This will more accurately estimate the contribution of nimodipine-sensitive channels at more negative potentials, at which block is incomplete with lower concentrations. It should be noted that Mogul and Fox previously performed a similar experiment. They found that $2 \mu \mathrm{M}$ nimodipine had agonist effects from a holding potential of $-90 \mathrm{mV}$, but not $-50 \mathrm{mV}$ (Mogul and Fox, 1991). In contrast, we saw no evidence for agonist effects of $10 \mu \mathrm{M}$ nimodipine from holding potentials of $-100,-80$, or $-50 \mathrm{mV}$. At all test potentials, current was inhibited. The two studies used very similar methods, with the only obvious exception being that Mogul and Fox used $\mathrm{Ba}^{2+}(5 \mathrm{~mm})$ as the charge carrier.

It is unlikely that $\mathrm{N}$ - or P-type channels contribute to the LVA sustained component, because $\omega$-CTX-MVIIC was without effect. However, the sustained component was partially inhibited by $\omega$-GsTx-SIA, raising the possibility that a "resistant" channel also may be active at low voltages. Currents resistant to nimodipine and $\omega$-CTx-MVIIC have been described previously in hippocampal neurons (McDonough et al., 1996).

\section{Nature of the LVA L-type channels}

It is of interest to know if the channels contributing to the LVA sustained component are classic L-type channels or a subpopula- tion of channels with similar pharmacology but a lower range of activation. Currently, it is difficult to distinguish between these two possibilities. A single Boltzmann adequately fit activation of the nimodipine-sensitive current (Fig. 8C). Hence, it is not necessary to invoke separate populations of L-type channels. The nimodipine-sensitive LVA current can be explained sufficiently as the foot of the activation curve for a homogenous population of L-type channels.

Nevertheless, we cannot rule out the possibility that the channels open at $-50 \mathrm{mV}$ represent a subpopulation of DHP-sensitive channels distinct from traditional L-type channels. Recent insights indicate the potential for extensive molecular diversity within the class of L-type channels. For example, mammals have at least two versions of the gene encoding the $\alpha_{1}$ subunit for L-type channels. These subunits may undergo alternative RNA splicing (Snutch et al., 1991) or combine with an array of associated subunits. The result may be a pool of functionally diverse channels, all of which fall under the grouping of "L-type." Such functional diversity has been described by single-channel recording within single types of cells (Forti and Pietrobon, 1993).

Recently, there have been other reports of sustained, nimodipine-sensitive currents at negative potentials (Thibault et al., 1993; Kavalali and Plummer, 1994; Marchetti et al., 1995). One functional role for a standing, nimodipine-sensitive current could be to modulate the resting $\left[\mathrm{Ca}^{2+}\right]_{i}$, as has been reported for hippocampal CA1 neurons (Johnston et al., 1995).

Our results make it clear that, in addition to T-type channels, at least one other type of channel can be activated with small depolarizations. L-type channels can be active at potentials much more negative than other HVA channels, where they may contribute to subthreshold $\mathrm{Ca}^{2+}$ signaling.

\section{REFERENCES}

Armstrong CM, Matteson DR (1985) Two distinct populations of calcium channels in a clonal line of pituitary cells. Science 227:65-67.

Artalejo CR, Dahmer MK, Perlman RL, Fox AP (1991) Two types of $\mathrm{Ca}^{2+}$ currents are found in bovine chromaffin cells: facilitation is due to the recruitment of one type. J Physiol (Lond) 432:681-707.

Bossu J-L, Feltz A (1986) Inactivation of the low-threshold transient calcium current in rat sensory neurones: evidence for a dual process. J Physiol (Lond) 376:341-357.

Brown AM, Tsuda Y, Wilson DL (1983) A description of activation and conduction in calcium channels based on tail and turn-on current measurements in the snail. J Physiol (Lond) 344:549-583.

Byerly L, Chase PB, Stimers JR (1984) Calcium current activation kinetics in neurones of the snail Lymnaea stagnalis. J Physiol (Lond) 348:187-207.

Carbone E, Lux HD (1984) A low-voltage-activated calcium conductance in embryonic chick sensory neurons. Biophys J 46:413-418.

Coulter DA, Huguenard JR, Prince DA (1989) Specific petit mal anticonvulsants reduce calcium currents in thalamic neurons. Neurosci Lett 98:74-78.

Destexhe A, Contreras D, Steriade M, Sejnowski TJ, Huguenard JR (1996) In vivo, in vitro, and computational analysis of dendritic calcium currents in thalamic reticular neurons. J Neurosci 16:169-185.

Eilers J, Augustine GJ, Konnerth A (1995) Subthreshold synaptic $\mathrm{Ca}^{2+}$ signaling in fine dendrites and spines of cerebellar Purkinje neurons. Nature 373:155-158.

Eliot LS, Johnston D (1994) Multiple components of calcium current in acutely dissociated dentate gyrus granule neurons. J Neurophysiol 72:762-777.

Fisher RE, Gray R, Johnston D (1990) Properties and distribution of single voltage-gated calcium channels in adult hippocampal neurons. J Neurophysiol 64:91-104.

Forti L, Pietrobon D (1993) Functional diversity of L-type calcium channels in rat cerebellar neurons. Neuron 10:437-450. 
Fox AP, Nowycky MC, Tsien RW (1987) Kinetic and pharmacological properties distinguishing three types of calcium currents in chick sensory neurones. J Physiol (Lond) 394:149-172.

Hablitz JJ, Johnston D (1981) Endogenous nature of spontaneous bursts in hippocampal neurons. Cell Mol Neurobiol 1:325-334.

Hagiwara N, Irisawa H, Kameyama M (1988) Contribution of two types of calcium currents to the pacemaker potentials of rabbit sino-atrial node cells. J Physiol (Lond) 395:233-253.

Herrington J, Lingle CJ (1992) Kinetic and pharmacological properties of low voltage-activated $\mathrm{Ca}^{2+}$ current in rat clonal $\left(\mathrm{GH}_{3}\right)$ pituitary cells. J Neurophysiol 68:213-232.

Hille B (1992) Modifiers of gating. In: Ionic channels of excitable membranes, pp 445-470. Sunderland, MA: Sinauer Associates.

Hume JR (1985) Comparative interactions of organic $\mathrm{Ca}^{2+}$ channel antagonists with myocardial $\mathrm{Ca}^{2+}$ and $\mathrm{K}^{+}$channels. J Pharmacol Exp Ther 234:134-140

Jahnsen H, Llinas R (1984) Ionic basis for the electroresponsiveness and oscillatory properties of guinea-pig thalamic neurones in vitro. J Physiol (Lond) 349:227-247.

Johnston D, Magee JC, Christie BR, Avery RB (1995) A steady-state, nimodipine-sensitive calcium current active at rest in hippocampal CA1 dendrites. Soc Neurosci Abstr 21:1742.

Jones SW, Jacobs LS (1990) Dihydropyridine actions on calcium currents of frog sympathetic neurons. J Neurosci 10:2261-2267.

Kamiya H (1989) Amiloride suppresses the induction of long-term potentiation in the mossy fiber pathway but not in the commissural/ associational pathway of the hippocampal CA3 region. Synapse 3:286-287.

Kavalali ET, Plummer MR (1994) Selective potentiation of a novel calcium channel in rat hippocampal neurones. J Physiol (Lond) 480:475-484.

Kuo C-C, Bean BP (1994) Slow binding of phenytoin to inactivated sodium channels in rat hippocampal neurons. Mol Pharmacol 46:716-725.

Llinás R, Yarom Y (1981) Properties and distribution of ionic conductances generating electroresponsiveness of mammalian inferior olivary neurones in vitro. J Physiol (Lond) 315:569-584.

Magee JC, Johnston D (1995a) Synaptic activation of voltage-gated channels in the dendrites of hippocampal pyramidal neurons. Science 268:301-304.

Magee JC, Johnston D (1995b) Characterization of single voltage-gated $\mathrm{Na}^{+}$and $\mathrm{Ca}^{2+}$ channels in apical dendrites of rat CA1 pyramidal neurons. J Physiol (Lond) 487:67-90.

Magee JC, Christofi G, Miyakawa H, Christie B, Lasser-Ross N, Johnston D (1995) Subthreshold synaptic activation of voltage-gated $\mathrm{Ca}^{2+}$ channels mediates a localized $\mathrm{Ca}^{2+}$ influx into the dendrites of hippocampal pyramidal neurons. J Neurophysiol 74:1335-1342.

Marchetti C, Amico C, Usai C (1995) Functional characterization of the effect of nimodipine on the calcium current in rat cerebellar granule cells. J Neurophysiol 73:1169-1180.

Markram H, Sakmann B (1994) Calcium transients in dendrites of neocortical neurons evoked by single subthreshold excitatory postsynaptic potentials via low-voltage-activated calcium channels. Proc Natl Acad Sci USA 91:5207-5211.

Matsuki N, Quandt FN, Eick RET, Yeh JZ (1984) Characterization of the block of sodium channels by phenytoin in mouse neuroblastoma cells. J Pharmacol Exp Ther 228:523-530.

McDonough SI, Swartz KJ, Mintz IM, Boland LM, Bean BP (1996) Inhibition of calcium channels in rat central and peripheral rat neurons by $\omega$-conotoxin MVIIC. J Neurosci 16:2612-2623.
Mogul DJ, Fox AP (1991) Evidence for multiple types of $\mathrm{Ca}^{2+}$ channels in acutely isolated hippocampal CA3 neurones of the guinea-pig. J Physiol (Lond) 433:259-281.

Niedermeyer E (1990) Phenytoin, other hydantoins, and further derivatives. In: The epilepsies: diagnosis and treatment, pp 277-288. Baltimore, MD: Urban and Schwarzenberg.

Ozawa S, Tsuzuki K, Iino M, Ogura A, Kudo Y (1989) Three types of voltage-dependent calcium current in cultured rat hippocampal neurons. Brain Res 495:329-336.

Palmer LG (1984) Voltage-dependent block by amiloride and other monovalent cations of apical $\mathrm{Na}^{+}$channels in the toad urinary bladder. J Membr Biol 80:153-165.

Piser TM, Lampe RA, Keith RA, Thayer SA (1995) $\omega$-Grammotoxin SIA blocks multiple, voltage-gated, $\mathrm{Ca}^{2+}$ channel subtypes in cultured rat hippocampal neurons. Mol Pharmacol 48:131-139.

Provencher SW (1976) A Fourier method for the analysis of exponential decay curves. Biophys J 16:27-41.

Regan LJ, Sah DWY, Bean BP (1991) $\mathrm{Ca}^{2+}$ channels in rat central and peripheral neurons: high-threshold current resistant to dihydropyridine blockers and $\omega$-conotoxin. Neuron 6:269-280.

Snutch TP, Tomlinson WJ, Leonard JP, Gilbert MM (1991) Distinct calcium channels are generated by alternative splicing and are differentially expressed in the mammalian CNS. Neuron 7:45-57.

Takahashi K, Akaike N (1991) Calcium antagonist effects on lowthreshold (T-type) calcium current in rat isolated hippocampal CA1 pyramidal neurons. J Pharmacol Exp Ther 256:169-175.

Takahashi K, Wakamori M, Akaike N (1989) Hippocampal CA1 pyramidal cells of rats have four voltage-dependent calcium conductances. Neurosci Lett 104:229-234.

Takahashi K, Ueno S, Akaike N (1991) Kinetic properties of T-type $\mathrm{Ca}^{2+}$ currents in isolated rat hippocampal CA1 pyramidal neurons. J Neurophysiol 65:148-155.

Tang C-M, Presser F, Morad M (1988) Amiloride selectively blocks the low-threshold (T) calcium channel. Science 240:213-215.

Thibault O, Porter NM, Landfield PW (1993) Low $\mathrm{Ba}^{2+}$ and $\mathrm{Ca}^{2+}$ induce a sustained high probability of repolarization openings of L-type $\mathrm{Ca}^{2+}$ channels in hippocampal neurons: physiological implications. Proc Natl Acad Sci USA 90:11792-11796.

Thompson SM, Wong RKS (1991) Development of calcium current subtypes in isolated rat hippocampal pyramidal cells. J Physiol (Lond) 439:671-689.

Turner TJ, Lampe RA, Dunlap K (1995) Characterization of presynaptic calcium channels with $\omega$-conotoxin MVIIC and $\omega$-grammotoxin SIA: role for a resistant calcium channel type in neurosecretion. Mol Pharmacol 47:348-353.

de Weille JR, Schweitz J, Maes P, Tartar A, Lazdunski M (1991) Calciseptine, a peptide isolated from black mamba venom, is a specific blocker of the L-type calcium channel. Proc Natl Acad Sci USA 88:2437-2440.

Yaari Y, Hamon B, Lux HD (1987) Development of two types of calcium channels in cultured mammalian hippocampal neurons. Science 235:680-682.

Yatani A, Brown AM (1985) The calcium channel blocker nitrendipine blocks sodium channels in neonatal rat cardiac myocytes. Circ Res $56: 868-875$.

Zhou W, Jones SW (1995) Surface charge and calcium channel saturation in bullfrog sympathetic neurons. J Gen Physiol 105:441-462. 